\title{
LA LEX AQUILIA: LA ESTRUCTURA DEL DAMNUM INIURIA DATUM Y SU EVOLUCIÓN A TRAVÉS DE LA INTERPRETATIO PRUDENTIUM Y LA ACTIVIDAD PRETORIA \\ THE LEX AQUILIA: THE STRUCTURE OF DAMNUM INIURIA DATUM AND ITS EVOLUTION THROUGH THE INTERPRETATIO PRUDENTIUM AND THE WORK OF THE PRAETORS
}

\author{
Luis Carlos Sánchez Hernández* \\ Universidad Externado de Colombia
}

\begin{abstract}
The Lex Aquilia, a third-century approved plebiscite, is the origin of the modern tortious liability on those legal systems descending from the roman system. Therefore, its study constitutes a necessity, because it allows us solid understanding of the previsions of the current civil codes, both in Europe as in Latin America.
\end{abstract}

This article analyses the content of the three chapters in the plebiscite and the possible procedural clauses that followed; then, we will examine the structural element of the damnun injuria datum, crime regulated by chapters first and third of this law, and the evolution that each of these elements has experienced through jurisprudential interpretation, as well. Also, we will discuss how the Praetor extended the scope of application of the Lex Aquila through praetor acts; and, finally, the author will present, synthetically, the state of affairs on Justinian codification.

KEY WORDS: lex Aquilia, damnum iniuria datum, extracontractual civil liability.
La Lex Aquilia del derecho romano, plebiscito aprobado en el siglo III a. C., es el origen del moderno régimen de responsabilidad civil extracontractual de aquellos ordenamientos que son parte del sistema jurídico romanista, por lo que su estudio constituye hoy por hoy una necesidad, pues nos permite una comprensión más sólida de las previsiones de los códigos civiles actuales, tanto europeos como latinoamericanos.

Por ello, el presente artículo analizará en una primera parte el contenido de los tres capítulos del plebiscito y las posibles cláusulas procesales que le seguían; luego en una segunda parte se analizaran los elementos estructurales del damnum iniuria datum, delito regulado por los capítulos primero y tercero de la ley, así como la evolución que sufrió cada uno de estos elementos a través de la interpretación de la jurisprudencia; en la tercera parte se analizará cómo la actividad del pretor amplió el campo de acción de la lex Aquilia mediante acciones pretorias; y por último se expondrá sintéticamente el estado de cosas en la Codificación de Justiniano.

Palabras clave: lex Aquilia, damnum iniuria datum, responsabilidad civil extracontractual.

\footnotetext{
Abogado. Doctor (Ph.D.) de la Università degli Studi di Roma "Tor Vergata" y magíster en Sistemas Jurídicos Contemporáneos, por la misma casa de estudios. Docente e investigador del Departamento de Derecho Romano de la Universidad Externado de Colombia. Contacto: luis.sanchez@uexternado.edu.co.
}

Nota del Editor: El presente artículo fue recibido por el Consejo Editorial de THËMIS-Revista de Derecho el 28 de marzo de 2018, y aceptado por el mismo el 4 de junio de 2018. 


\section{INTRODUCCIÓN}

Si bien la Lex Aquilia representó un momento paradigmático en la historia del Derecho de Daños, no fue el primer cuerpo legislativo que tuvo por objeto sancionar determinadas conductas que causaban un daño a un bien ajeno. Ya desde el siglo IV a. C. la Ley de las XII Tablas había previsto específicos supuestos de daños patrimoniales, tales como el daño causado por animales (actio de pauperie), la tala injustificada de árboles ajenos (actio de arboribus succisis), el incendio de edificios o sembrados ajenos (actio aedium incensarum), el pastar o dañar de noche predios ajenos (actio de pastu pecoris), y la lesión física a un esclavo (os fractum), entre otros (Giofredi, 1980, p. 4; Valditara, 2005, p. 3; Corbino, 2005, p. 23; Cursi, 2010, p. 3$)^{1}$.

En consecuencia, la aprobación de la Lex Aquilia, aproximadamente en el siglo III a. C. (Cannata, 1995a, p. 31; Cursi 2002, p. 147; Valditara, 2005, p. 6; Corbino, 2005 , p. 48) ${ }^{2}$, representó una profunda transformación del régimen existente en su época. La innovación consistió en unificar en un único texto -compuesto, como veremos a continuación, por tres capítulos y, probablemente, dos cláusulas procesales- las principales hipótesis de daño a un bien ajeno, derogando de esta manera el esquema fuertemente casuístico precedente, proveniente principalmente de la regulación decenviral, y superando ciertos esquemas que resultaban ya inútiles para la sociedad romana de la época, tales como las penas fijas propias de algunos ilícitos de las XII Tablas y que resultaron a la postre obsoletas por la desvalorización monetaria (Valditara, 2005, p. 16).

Justamente, del hecho que la legislación aquiliana tuvo por finalidad unificar las reglas que sancionaban el daño a una cosa ajena, nos da noticia Ulpia- no, en el libro XVIII de sus Comentarios al edicto ${ }^{3}$, donde afirmó que esta ley fue un plebiscito que hizo votar un tribuno de la plebe de nombre Aquilio, el cual derogó todas las leyes que antes habían tratado el daño causado con iniuria. Sobre este particular, como acertadamente sostiene Cannata (1995a, p. 25), el hecho que el jurista Severiano haya utilizado el verbo derogare mas no abrogare denota, precisamente, que la Ley Aquilia no tuvo por efecto sustituir enteramente la regulación decenviral, sino solamente aquellas normas que hacían referencia a supuesto de daños patrimoniales causados con iniuria, es decir, que coincidían con las previsiones de la Lex Aquilia. Así, por ejemplo, la actio de pauperies mantuvo siempre su vigencia y aplicabilidad, pues, si bien sancionaba un daño causado a una cosa ajena, el supuesto era del todo diverso al ilícito aquiliano.

Conviene entonces comenzar por ocuparnos de analizar el contenido del plebiscito aquiliano.

\section{EL CONTENIDO DEL PLEBISCITO AQUILIANO}

Acerca del contenido de nuestro plebiscito, con seguridad se conoce que estaba compuesto por tres capítulos, que han llegado a nuestros días gracias a las obras de juristas clásicos, especialmente de Ulpiano y Gayo, cuya descripción es más o menos fiel respecto a su contenido originario Cannata (2012a, p. 9) ${ }^{4}$. A los tres capítulos, como la doctrina reciente ha formulado, posiblemente le seguían dos cláusulas de naturaleza procesal.

\section{A. El primer capítulo}

Del contenido del primer capítulo de la Lex Aquilia nos dan noticia dos pasajes de Gayo: uno de sus Comentarios al edicto provincial (Gai. 7 ad ed. prov. D.9,2,2 $\mathrm{pr}^{5}$.) y otro de sus Instituciones (Gai.

Sobre la legislación decenviral y, en general, la anterior a la Lex Aquilia en materia de daño patrimonial, véase, entre otros.

2 Sobre la datación de la Lex Aquilia, la superación de la tesis según la cual el plebiscito fue aprobado en la secesión plebeya del 287-286 a. C. y la imposibilidad establecer una fecha cierta de su promulgación, cfr., entre otros.

3 Ulp. 18 ad ed. D.9,2,1. Lex Aquilia omnibus legibus, quae ante se de damno iniuria loutae sunt, derogavit, sine alia quae fuit: quas leges nunc referre non est necesse. Quae Lex Aquilia plebiscitum est, cum eam Aquilius tribunus plebis a plebe rogaverit. [Trad.: La ley Aquilia derogó todas las leyes que antes de ella trataron del daño con iniuria, así la de las Doce Tablas, como alguna otra que hubo; cuyas leyes no es necesario referir ahora. Cuya ley Aquilia es un Plebiscito, puesto que la presentó a la aprobación de la plebe el Tribuno de la plebe Aquilio.]

La versión latina de este y todos los fragmentos del Digesto de Justiniano citados en este trabajo fueron tomados de: Mommsen y Krueger (1870). La versión en español de este y todos los fragmentos del Digesto de Justiniano citados en este trabajo fueron tomados de: García del Corral (1889).

$4 \quad$ Luego de hacer un análisis de las palabras usadas por Ulpiano y Gayo en los fragmentos que reportan el contenido de la Lex Aquilia, afirma el evidente acceso y conocimiento de estos juristas al texto original de la ley, y fue con base en él que escribían sus comentarios, en algunos casos modernizando la lengua de la ley aprobada aproximadamente tres siglos antes, mientras en otros casos reportando arcaísmos propios del lenguaje legislativo original.

5 Gai. 7 ad ed. prov. D.9,2,2 pr. Lege Aquilia capite primo cavetur: 'ut qui servum servamve alienum alienamve quadrupedem vel pecudem iniuria occiderit, quanti id in eo anno plurimi fuit, tantum aes dare domino damnas esto'. [Trad.: Dispónese en el capítulo primero de la ley Aquilia: 'que el que hubiere matado con iniuria al esclavo o a la esclava ajenos, a un cuadrúpedo, o a una res, sea condenado a pagar al dueño el precio mayor que aquello tuvo en aquel año'] 
$3.210^{6}$ ), este último fue reproducido casi intacto en un fragmento de las Instituciones de Justiniano (I.4,3 pr.).

Estos fragmentos de Gayo permiten reconstruir el contenido del primer capítulo de la ley, cuyo objeto era sancionar a aquel que matara con iniuria a un esclavo o pecus ajeno, condenándolo a pagar al propietario de la cosa el mayor valor que ella hubiera tenido en el año anterior.

De la previsión legislativa resulta importante en esta sede precisar cuáles eran los bienes tutelados ex capite primo. La expresión servum servamve alienum alienamve usada por Gayo en sus Comentarios al edicto se distancia de aquella utilizada en su texto Institucional hominem alienum. Respecto a ello, la doctrina afirma que la primera es la más cercana al detalle original del texto legislativo, a pesar de su carácter redundante (el siervo y la sierva, ajeno y ajena), pues era la expresión del estilo del legislador republicano que estaba condicionado por el formalismo interpretativo reinante en la época. En cambio, en el texto Institucional el jurista prefirió usar hominem alienum que para la época de esta obra era una expresión más apta para indicar un esclavo o esclava ajeno (Cannata, 2012a, p. 14; Cursi, 2002, p. 169).

Mayor dificultad ha presentado la reconstrucción de la parte del fragmento referente a los animales tutelados ex capite primo. La expresión que según la doctrina es más cercana al texto original de la ley es la contenida en los Comentarios al edicto de Gayo: quadrupedem vel pecudem (Cannata, 2012a, p. 13; Cursi, 2002, p. 171; 2010, p. 28)7.

La jurisprudencia se encargó de concretar la categoría de los pecudes, en este sentido, Gayo en sus Comentarios al edicto (Gai 7 ad ed prov. D.9,2,2, $2^{8}$ ), luego de testimoniar la equiparación legal entre los esclavos y estos animales, nos dio noticia de cuáles animales se consideraban comprendidos entre los pecudes y de cómo este tema suscitó la atención de los prudentes.

En este sentido, la jurisprudencia delimitó la categoría de pecus a todo animal que fuera cuadrúpedo y que además fuera gragatin habentur, es decir, que estuviera en rebaño (Corbino, 2005, p. 66). Dentro de esta categoría Gayo indicó, a título ejemplificativo, que se encontraban incluidos las ovejas, las cabras, los bueyes, los caballos, los mulos y los asnos; dudó respecto de los cerdos, a lo que Labeón favoreció su inclusión; en cambio, fueron excluidos los perros y los animales feroces como los osos, leones y panteras; mientras que los elefantes y camellos tenían una naturaleza mixta pues, siendo feroces por naturaleza, eran empleados al servicio del hombre.

De la atenta lectura de esta noticia gayana, se deduce que la tutela de estos animales se justificaba

6 Gai. 3.210. Damni iniuriae actio constituitur per legem Aquiliam, cuius primo capite, cautum est, ut si quis hominem alienum alienamve quadrupedem quae pecudum numero sit iniuria occiderit, quanti ea res in eo anno plurimi fuit, tantum domino dare damnetur. [Trad.: La acción de daño injusto es establecida por la ley Aquilia, en su primer capítulo se dispone que, si alguien mata injustamente a un esclavo ajeno o a un cuadrúpedo ajeno de cualquier clase de ganado, sea condenado a dar al dueño el mayor valor que esa cosa haya tenido en aquel año.] La versión latina de este y todos los fragmentos de las Instituciones de Gayo citadas en este trabajo fueron tomadados de: Seckel; Kübler (1909). La versión en español de este y todos los fragmentos de las Instituciones de Gayo fueron tomados de la traducción de Iglesias, Roset, Abellán y Arias (1985).

$7 \quad$ Esta es la expresión original que se lee en la Littera Florentina pero la doctrina mayoritaria y las diversas ediciones del Digesto han optado por corregir la expresión reemplazándola por quadrupedemve pecudem que hace más coherente el testimonio de Gayo. Sin embargo, que esta expresión, tal como fue reportada por el jurista clásico, estuviese en el texto legislativo ha suscitado dudas en la doctrina. Cursi (2002, p. 173), apoyando la corrección mencionada, propone la originalidad de la expresión quadrupedemve pecudem en el texto legislativo. Afirma la autora que la palabra pecus, según testimonian fuentes antiguas, tenía un significado amplio que indicaba todo género de animal, y con la locución quadrupedemve pecudem el legislador pretendió limitar la aplicación de la norma a los animales que fueran cuadrúpedos; mientras la interpretación de la jurisprudencia se concentró en definir la categoría, excluyendo algunos animales cuadrúpedos de la categoría de pecudes. En cambio, Cannata (2012, p. 15) en su trabajo de reconstrucción del texto aquiliano, propone que la expresión utilizada originalmente por el legislador fue vel pecudem y la mención a los quadrupes fue el resultado de una glosa mal inserida en época prejustinianea, conjeturando que quien la realizó, lo hizo pensando en la precisión hecha por Gayo en el Texto institucional (Gai. 3,210) al indicar quadrupes quae pecudem numero sit que no era la noticia del texto original.

8 Gai. 7 ad ed. prov. D.9,2,2,2. Ut igitur apparet, servis nostris exaequat quadrupedes, quae pecudum numero sunt et gregatim habentur, veluti oves caprae boves equi muli asini. sed an sues pecudum appellatione continentur, quaeritur: et recte Labeoni placet contineri. Sed canis inter pecudes non est. longe magis bestiae in eo numero non sunt, veluti ursi leones pantherae. elefanti autem et camelli quasi mixti sunt (nam et iumentorum operam praestant et natura eorum fera est) et ideo primo capite contineri eas oportet. [Trad.: Así, pues, según se ve, equipara con nuestros esclavos a los cuadrúpedos, que se comprenden en la clase de ganados, y se tienen en piaras, como las ovejas, las cabras, los bueyes, los caballos, los mulos, y los asnos. Pero preguntase si los cerdos se contienen en la denominación de ganados; y con razón parece bien a Labeón que se contienen; pero el perro no se comprende en la denominación de ganados. Con más razón tampoco se comprenden en el número de éstos las fieras, como los osos, los leones y las panteras; pero los elefantes y los camellos son como de género mixto (porque prestan el servicio de los jumentos y es de fiera su naturaleza) y por lo tanto deben ser comprendidos en el primer capítulo.] 
en su relevancia económica para el dominus, la cual se explicaba tanto por la mayor utilidad que representaban, como por su limitada disponibilidad (Cursi, 2002, p. 174). Por lo tanto, no se tenía en consideración la condición natural del animal, sino su importancia económica, pues eran animales susceptibles de reducirse al servicio del hombre y su organización en rebaño acrecía su valor, ya que permitía un mejor disfrute económico ligado a la reproducción y la cualidad de sus productos (Corbino 2005, p. 67).

Lo anterior resulta confirmado, por un lado, por la locución operam praestare que Gayo utilizó para incluir a los elefantes y camellos, pues el criterio era el empleo de estos animales en la agricultura, mas no su naturaleza de animales feroces y, por otro lado, por la equiparación de los esclavos a estos animales, ya que los esclavos eran bienes de especial valor por su disfrute económico y por las que habilidades podían obtener y, por ello, eran objeto de un tratamiento privilegiado, el cual el legislador extendió a los animales que eran empleados en actividades económicas, principalmente agrícolas, pues su destrucción en uno u otro caso derivaba en un especial perjuicio a su propietario (Corbino, 2005, p. 69).

\section{B. El segundo capítulo}

El segundo capítulo del plebiscito aquiliano no constituye objeto de este trabajo, tanto por su pronta caída en desuso, como porque la hipótesis que regulaba excede la materia del damnum iniuria datum. Sin embargo, resulta oportuno hacer algunas anotaciones especialmente en lo que tiene que ver con la relación de este capítulo con los otros dos. Tres fuentes recuerdan la existencia de este capítulo del plebiscito, de las cuales sólo una de ellas, de las Instituciones de Gayo, reporta su contenido (Gai. $3.215^{\circ}$ ), mientras las dos restantes, una de los Comentarios al edicto de Ulpiano (UIp. 18 ad ed. D.9,2,27, $4^{10}$ ) y otra de las Instituciones de Justiniano $\left(1.4,3,12^{11}\right)$, recuerdan su rápida caída en desuso.

La doctrina mayoritaria ha sostenido que la hipótesis sancionada, tal como Gayo la describe en su texto Institucional, consistía en: la remisión, mediante acceptilatio verbal, que el adstipulator hacía en favor del promissor y en fraude al acreedor principal, cuya sanción era una condena pecuniaria al adstipulator y en favor del acreedor principal, por una suma de dinero igual a la del crédito extinto (de Robertis 2000, p. 35; Pugsley, 1972 , p. 489) ${ }^{12}$

Sin embargo, la introducción de la actio mandati, por ser un remedio de naturaleza reipersecutoria, resultó ser un instrumento más eficaz para el acreedor principal contra su adstipulator, lo cual determinó la rápida caída en desuso de la acción ex capite secondo (Cannata, 2012b, p. 121).

Son dos las cuestiones que han llamado la atención de la doctrina romanista, en primer lugar, la definición misma de la conducta sancionada y, en segundo lugar, el hecho que la misma parecería romper la lógica de la regulación aquiliana, por cuanto en el primer capítulo tutelaba al propietario contra la destrucción de bienes de especial valor económico y en el tercero, como se verá, contra el deterioro o destrucción de los demás bienes corporales.

Con relación a la conducta sancionada, es decir la acceptilatio, Lévy-Bruhl (1958, p. 507) ha propues-

9 Gai. 3.215. Capite secundo <adversus> adstipulatorem qui pecuniam in fraudem stipulatoris acceptam fecerit, quanti ea res est, tanti actio constituitur. 216 Qua et ipsa parte legis damni nomine actionem introduci manifestum est; sed id caveri non fuit necessarium, cum actio mandati ad eam rem sufficeret; nisi quod ea lege adversus infitiantem in duplum agitur. [Trad.: En el segundo capítulo se establece una acción contra el coestipulante que se hubiera dado por pagado en fraude del estipulante. 216 Es evidente que en esa misma parte de la ley se ha introducido tal acción a título de daño; pero esto no era necesario disponerlo, ya que bastaba para ello la acción de mandato, aunque por esta ley se puede ejercitar una acción al doble contra el demandado que niega el hecho].

10 Ulp. 18 ad ed. D.9,2,27,4. Huius legis secundum quidem capitulum in desuetudinem abiit. [Trad.: El segundo capítulo de esta ley cayó ciertamente en desuso.]

11 I.4,3,12. Caput secundum legis Aquiliae in usu non est. [Trad.: El segundo capítulo de la ley Aquilia no está en uso.]

12 En cambio ha afirmado, basado en la teoría de la formación progresiva de la Lex Aquilia (cfr. infra), que se trataba de una norma de carácter ejecutivo y procesal que continuaba al único original primer capítulo de la ley. Según su reconstrucción, el adstipulator era un intermediario entre el agente y la víctima, que era de nómina oficial y habilitado para recibir la summa aestimationis de la condena resultante de la acción ex lege Aquilia y por tanto liberar al deudor de su obligación y del consecuente vinculo personal (nexum) contraído. Siendo este intermediario un adiectus solutionis causa necessarius para evitar que el acreedor mantuviera a su deudor en situación servil o para-servil. Así, para el autor la causa de la desuetud de esta norma fue la desaparición de la servidumbre personal de los deudores como garantía de sus deudas. Por otro lado, Pugsley ha propuesto que, excluyendo la existencia de la categoría del adstipulator en la época de la aprobación de la ley, la hipótesis que pretendía sancionar consistía en la destrucción por parte del mismo deudor del esclavo o pecus debido, en fraude a su acreedor. Creando de esta manera una estrecha relación entre el I y II capítulo que tutelaría respectivamente la destrucción de una cosa objeto de una relación real y de una relación obligacional. Ambas tesis, según la doctrina, resultan del todo conjeturales y alejadas de la descripción gayana. 
to que, en la época de la aprobación del plebiscito, dada la vigencia del principio del contrarius actus, esta figura constituía el modo normal y necesario de extinguir una obligación verbis contracta y, por lo tanto, comportaba el pago real. En este sentido, la conducta sancionada no era la acceptilatio del adstipulator en sí misma, sino el hecho que retuviera para sí el dinero recibido.

Tomulescu (1970, p. 192), en cambio, ha notado que siendo la acceptilatio en el derecho antiguo necesaria y suficiente para extinguir una obligación nacida de una stipulatio, la misma podía o no estar precedida por el pago real, por lo tanto, sostiene el autor que la disposición aquiliana pretendió sancionar tanto que el adstipulator hubiera recibido el pago real reteniéndolo para sí, como la colusión entre él y el deudor, mediante la liberación sin el efectivo pago.

Recientemente Cannata (2002b, p. 125), cuya posición resulta la más aceptada por la doctrina (Cursi, 2002, p. 184; Valditara, 2005, p. 11; Corbino $(2005$, p. 35$)$, primero, pone de relieve que las teorías propuestas por Lévy-Bruhl y Tomulescu se alejan de la hipótesis descrita por Gayo, que consiste en una acceptilatio fraudulenta, pues, según los criticados autores, la conducta reprochada no sería la acceptilatio en sí misma, sino el hecho de retener el producto del pago para sí por el adstipulator, lo cual se distancia absolutamente de la descripción gayana.

Luego, el autor argumenta que la acceptilatio desde que fue creada por la jurisprudencia laica del siglo III a. C., tuvo por función exclusivamente la remisión de un crédito nacido de una promesa verbal y formal. Por lo tanto, ya que la extinción de la obligación avenía por una causa diferente al pago, debía realizarse mediante un acto formal, y para tal fin la jurisprudencia creó la acceptilatio. En consecuencia, concluye Cannata que el supuesto sancionado por el segundo capítulo de la Lex Aquilia era la remisión del crédito realizada fraudulentamente $y$, por lo tanto, en perjuicio del acreedor principal.

Respecto de la ubicación de este supuesto dentro del contexto legislativo aquiliano, la determinación de la naturaleza del bien tutelado, es decir, el significado de la expresión pecunia, ha permitido a la doctrina explicar la razón de ser de su ubicación y de su tratamiento diferenciado. Grosso (1965, p. 128) ha propuesto que el legislador en el segundo capítulo pensaba en la destrucción de un crédito, por cuanto un obligatus venía liberado de su débito, anticipando lo que a la postre sería la concepción del crédito como res incorporalis. Por lo tanto, la lógica del legislador habría sido, según este autor, tutelar los bienes corporales de especial relevancia en el primer capítulo, el crédito como bien incorporal en el segundo y los demás bienes corporales en el tercero.

De otro lado, la tesis que parece más atendible es aquella propuesta por Cannata (1995a, p. 128), quien afirma que el legislador razonó respecto de la pecunia objeto de la fraudulenta acceptilatio en términos de una cosa material, es decir, de cualquier bien mueble que pudiera ser objeto de una stipulatio; la cual, en la hipótesis prevista por el legislador, no había sido destruida, sino más bien se había perdido a causa de la conducta fraudulenta del adstipulator (Corbino, 2005, p. 40).

Por lo tanto, la estructura normativa estaba articulada, según este autor, en el siguiente modo: la supresión de un esclavo o animal ajeno, la supresión de un crédito ajeno, entendido como la cosa material objeto de la obligatio y la supresión cualquier otra cosa ajena; tratándose de tres hipótesis diferenciadas tanto en la sanción impuesta como en el régimen de imputación, por cuanto, en el segundo capítulo sólo era relevante la conducta que era fraudulenta, es decir, dolosa (Cannata, 2012a, p. 43).

\section{El tercer capítulo}

La reconstrucción del contenido del tercer capítulo de la Lex Aquilia ha sido la que mayores problemas ha suscitado en la doctrina. Son varias las fuentes que dan noticia de este capítulo: una de las Instituciones de Gayo (Gai. 3,217), otra de las Instituciones de Justiniano $(I .4,3,13)$ y otra del libro 18 de los Comentarios al edicto de Ulpiano (Ulp. 18 ad ed. $\left.\mathrm{D} \cdot 9,2,27,5^{13}\right)$, la cual ha sido referida por la doctrina como la más cercana al detalle legislativo (Cursi, 2002, p. 186).

Con base en las fuentes que reportan su noticia, se puede afirmar que el supuesto contendido

13 Ulp. 18 ad ed. D.9,2,27,5. Tertio autem capite ait eadem Lex Aquilia: 'Ceterarum rerum praeter hominem et pecudem occisos si quis alteri damnum faxit, quod usserit fregerit ruperit iniuria, quanti ea res erit in diebus triginta proximis, tantum aes domino dare damnas esto'. [Trad.: Mas el tercer capítulo dice la misma ley Aquilia: 'Respecto a las demás cosas, excepto el esclavo y las reses que hayan sido muertos, si alguien hiciere daño a otro, porque hubiere quemado, quebrado o roto alguna cosa con iniuria, sea condenado a pagar al dueño tanto cuanto aquella cosa valiere en los treinta días próximos.] 
en capítulo tercero del plebiscito aquiliano establecía: respecto de las demás cosas (aquellas no comprendidas en el primer capítulo), si alguien hiciera daño a otro porque quemó, hizo pedazos o rompió alguna cosa con iniuria; será condenado a pagar al dueño el valor que la cosa tuviera en los 30 días anteriores.

Con relación a esta descripción conviene detenerse a analizar, por un lado, cuáles eran los bienes objeto de tutela ex capite tertio y, por otro lado, cuál era el periodo de tiempo respecto del cual se debía calcular el valor de la cosa que constituía el quantum de la condena.

Sobre los bienes tutelados, en la primera parte de la noticia ulpianea el jurista los delimitó mediante la expresión ceterarum rerum praeter hominem et pecudinem occisos. Según Cannata (1995a, p. 44; 1995c, p. 121), esta frase es parcialmente original respecto del detalle legislativo (Cardascia, 1974, 60; Valditara, 2005, p. 13) ${ }^{14}$, puesto que el capítulo tercero originalmente sólo tutelaba al propietario respecto de la destrucción total un bien, y por ello no preveía la destrucción parcial de los esclavos y animales, pues de no ser así un propietario que sufría la destrucción de un animal o un siervo recibiría una suma casi equivalente (el valor de la cosa), a la que recibiría el propietario que sufría sólo un deterioro parcial, causado por una herida, lo cual resultaría una disposición del todo inequitativa que no puede atribuírsele al legislador aquiliano (Bignardi, 1997, p. 37).

Así, entiende el autor que la frase praeter et hominem pecudinem occisos fue una agregación posterior $^{15}$ y afirma, en cambio, la originalidad de la expresión ceterarum rerum con la cual el legislador quiso significar las demás cosas (Cursi, 2002, $191)^{16}$, es decir, las que no estaban incluidas en el capítulo primero, dándole un sentido material a la locución res y ligándola con "si quis alteri damnum faxit [...]", que significaría "respecto de las demás cosas, si alguien causó un daño a otro [...]" (Cannata, 1995a, p. 44; Cursi, 2002, p. 190).

La exclusión de los esclavos y animales permaneció hasta que la jurisprudencia clásica reinterpretó la locución res de la parte condenatoria de la norma: quanti ea res erit, lo cual, como se verá más adelante, implicó que la condena dejó de ser por el valor de la cosa para reconocer al propietario el id quod interest. Sólo luego de esto, la jurisprudencia pudo integrar al tercer capítulo los deterioros no destructivos de un esclavo o animal, pues el propietario ya no recibía el valor integro de la cosa, sino el valor del daño efectivamente sufrido, y fue esta la precisión que Ulpiano hizo cuando en su comentario incluyó praeter et hominem pecudinem occisos que, más que una aclaración, era la nueva interpretación que la jurisprudencia le había dado al texto legislativo.

En lo referente al uso por parte de Ulpiano del verbo erit en futuro en la parte sancionatoria de la norma: quanti ea res erit in diebus triginta proximis, tantum aes domino dare damnas esto, la frase, según una lectura literal del texto, indicaría que el agente debía pagar al dueño de la cosa lo que la misma valiera en los 30 días siguientes.

Para la doctrina mayoritaria el uso de este verbo en futuro fue, sin duda, un error del copista de la Littera Florentina (Daube, 1936, p. 3; Cursi, 2002, p. 187; Cannata, 1995c, p. 121) ${ }^{17}$. A esta conclusión se llega por dos razones, primero, porque Gayo en sus Instituciones (Gai. 3,217), cuando parafraseó el supuesto regulado en el tercer capítulo de la Lex Aquilia, usó el verbo al perfecto fuerit y, el mismo Ulpiano, cuando citó una parte de la norma para

14 Cardascia sostiene la originalidad total de la frase, afirmado que en la expresión ceterarum rerum la referencia a res adoptaba el significado de casos mas no cosas, no ligado a los homines et pecudes sino al hecho de la muerte, y así, se permite afirmar el autor, que la tutela ex capite tertio abarcaba a los esclavos y animales cuando el daño fuere parcial. Valditara en cambio afirma que la expresión en su totalidad no era parte del detalle original de la ley, y por tanto, no concentra su atención en el significado de la palabra res; el autor propone que el capítulo tercero era una norma de cierre, con carácter general y dentro de su tutela se incluían tanto los esclavos y animales cuando el daño fuere no destructivo, como todas las demás cosas inanimadas.

15 Sustentado principalmente en el uso de la expresión hominem para indicar los esclavos, que, como se vio, no era la que el legislador utilizó en el primer capítulo de la ley, y en cambio, es la expresión que se adapta al lenguaje de los juristas clásicos, incluido Ulpiano que lo usó en los sucesivos fragmentos de la misma obra (Ulp. 18 ad ed. D.9,2,27,6).

16 Lo cual resulta coherente con el sentido que dentro del mismo cuerpo legislativo tiene la expresión res, la cual aparece en otra ocasión en el tercer capítulo y una vez en el primer capítulo, siempre en un sentido material.

17 Por el contrario, Daube sostiene que el uso del futuro erit era el original tanto del fragmento de Ulpiano como del texto legislativo y con base en ello sustenta enteramente su teoría, según la cual el tercer capítulo estaba destinado en principio a tutelar los mismos bienes del primero, pero respecto de los hechos que causaran un deterioro no destructivo; por lo tanto, para la cuantificación del valor de la cosa se tomaban los treinta días siguientes, puesto que el daño podía ser progresivo dejando o no secuelas en el animal o esclavo. Así la expresión ceterarum rerum praeter hominem et pecudinem occisos fue, para este autor, una agregación posterior producto de la ampliación del ámbito de tutela ex capite tertio a las cosas inanimadas, lo cual habría sucedido hacia la segunda mitad del siglo I a. C., y en cambio, el uso del verbo erit sí era original del texto aquiliano. Sobre las principales críticas que la doctrina ha expuesto a esta teoría. 
comentarla, en Ulp. 18 ad ed. D.9,2,29,8, utilizó el verbo fuit también referente al pasado (Valditara, 2005, p. 10).

Segundo, porque en estas mismas dos fuentes, al comentar la cláusula sancionatoria del tercer capítulo, ambos juristas notaron la ausencia del plurimi que, en cambio, sí aparece en el primer capítulo, por lo tanto, resulta imposible pensar, teniendo en cuenta la rigurosidad de los juristas en mención, que comparando el texto legislativo de uno y otro capítulo, no se hayan percatado o hayan omitido la mención de que el periodo para la cuantificación del daño era pasado en el primero y futuro en el tercero (Cannata, 1995c, p. 124). Por lo tanto, se debe concluir que el arco de los 30 días para cualificar el valor de la cosa, eran los anteriores al acaecimiento del daño.

\section{La posible formación progresiva de la lex Aquilia y las cláusulas procesales}

Conviene examinar la hipótesis que una parte de la doctrina romanista ha sostenido con relación a la posible formación progresiva de la Lex Aquilia. Esta propuesta nace principalmente a causa de la relevante falta de homogeneidad en el contenido de los tres capítulos, en especial, por la colocación del segundo que rompe la continuidad de las previsiones del primero y el tercero (Cursi, 2002, p. 208; Valditara, 2005, p. 11) ${ }^{18}$.

Para quienes apoyan la estratificación del texto legislativo, son dos las noticias de Gayo que pueden ofrecer indicios al respecto. Por un lado, cuando el jurista en su texto Institucional dio noticia del contenido del segundo capítulo (Gai. 3,216), es claro el intento de justificar la heterogeneidad de su contenido con la lógica de los demás capítulos y, por ello, recuerda a sus lectores que este capítulo de la ley también se refería al damnum.

Esta aclaración del jurista podría constituir un testimonio de la estratificación del texto, dado que la locución damnum sólo aparece en el texto del tercer capítulo y, por lo tanto, la insistencia de considerar esta noción sustancialmente presente también en el segundo, podría ser un in- dicio de una posterior relectura jurisprudencial de un texto más arcaico -el primer y segundo capítulo-, a la luz de una agregación sucesiva -el tercero- y así lograr una mayor armonía (Cursi, 2002, p. 210).

Por otro lado, también sería un indicio la manera en la cual Gayo hizo referencia a la cláusula de la litiscrescenza en caso de adversus infitiantem, la cual fue recordada por el jurista sólo respecto de los dos primeros capítulos. En el primero, luego de citar textualmente su contenido, indicó que dicha cláusula se encontraba más adelante (infra $)^{19}$, es decir, no inmediatamente; en cambio, respecto del segundo capítulo, el jurista estableció una conexión directa entre el contenido de mismo y la cláusula (Gai. 3.216), lo cual permitiría pensar que la lex estaba compuesta originariamente sólo por estos dos capítulos y, seguidamente, la referida cláusula procesal.

Estos argumentos no son decisivos, pero han permitido al menos afirmar que existe la posibilidad de que el texto legislativo haya sido construido progresivamente. En cambio, los autores que rechazan dicha estratificación, lo hacen principalmente sobre la base de que existe una coherencia entre los tres capítulos, según como cada unos de estos autores ha propuesto su propia reconstrucción del detalle legislativo (Cannata, 1995a, p. 43; 2012a, p. 9; Valditara, 2005, p. 12). En cualquier caso, ambas posiciones son hasta ahora difíciles de demostrar, no obstante, la afirmación de Ulpiano en Ulp. 18 ad ed. D.9,2,1 nos permite al menos concluir que los juristas analizaron la Lex Aquilia como un solo cuerpo legislativo único compuesto por tres capítulos.

Por último, resta considerar una hipótesis sostenida recientemente, según la cual, en el texto legislativo, a los tres capítulos les seguía dos cláusulas de naturaleza procesal. Una de ellas hacía referencia a la litiscrescenza en caso de adversus infitiantem, mientras que la otra contemplaba la regla de la relevancia de la scientia domini y, por tanto, en caso de un daño cometido por un siervo, esta cláusula introdujo la posibilidad de promover la acción directa contra el dominus sciens.

1 Las teorías acerca de la posible estratificación del texto legislativo han sido variadas: unos han pensado en la existencia de una anterior lex Satura compuesta de dos capítulos: uno referente a la destrucción de bien animado y el otro a la de un crédito y sólo posteriormente, hacia el siglo III a. C., se habría modificado el primer capítulo y agregado el supuesto de daño no destructivo, mediante un tercer capítulo. Otros han individuado por lo menos cinco estratos de la Lex Aquilia, que, según la técnica legislativa propiamente republicana, por aproximaciones sucesivas habría llevado a la definitiva generalización de la hipótesis prevista en el tercer capítulo. Hay también quienes han pensado que se trataban de tres leyes distintas que, sólo luego, fueron nominadas bajo una sola lex. Y, en fin, se ha pensado que el segundo capítulo se trató de quelque accident en la tradición del texto que llevó a su incoherente ubicación.

19 Gai. 7 ad ed. prov. D.9,2,2,1. Et infra deinde cavetur, ut adversus infitiantem in duplum actio esset. [Trad.: $Y$ después dispónese además que la acción fuese por el duplo contra el que negase.] 
La cláusula de litiscrescenza en caso de adversus infitiantem, consistía en que contra aquel que negaba haber cometido el hecho dañoso, pero luego era reconocido autor de este, la condena era impuesta por el doble del valor de la cosa, mientras que si el reo confesaba (confitens), la condena era impuesta in simplum (de Robertis, 2000, 38; Talamanca, 1990, p. 337). De la posible existencia de esta cláusula procesal en el detalle legislativo, nos da noticia Gayo en dos diferentes lugares: en sus Comentarios al edito provincial donde, relatando el texto del primer capítulo, afirmó Et infra deinde cavetur, utadversus infitiantem in duplum actio $e s t^{20}$, y también en su texto Institucional, cuando, dando noticia del contenido del segundo capítulo, aseveró ...quod ex lege adversus infitiantem in duplum agitur ${ }^{21}$.

Sobre estos dos testimonios gayanos, la doctrina mayoritaria (Corbino, 2005, p. 33) ${ }^{22}$ ha sostenido que se trababa de una cláusula general de la $a c$ tio ex lege Aquilia, la cual era una norma expresa y autónoma, pero no calificada como capítulo, pues no se trataba de una norma sustancial sino de una regla procesal aplicable a todos los capítulos y a su respectiva parte sancionatoria (Cannata, 1990, p. 34; Cursi, 2002, p. 212).

Luego, acerca de la cláusula que da relevancia a la scientia domini, esta establecía una excepción la regla de la noxalidad de la actio ex lege Aquilia, regla que descendía del carácter penal de la acción, según la cual, en caso de un daño cometido por un esclavo o animal ajeno, el dominus se liberaba del pago de la pena entregando en cambio el esclavo o el animal al propietario de la cosa dañada. La excepción, según el testimonio de Ulpiano ${ }^{23}$, consistía en que, cuando el dominus tenía conocimiento de la intención de dañar de su esclavo (scientia domini) y no lo evitaba, la víctima podía ejercitar la acción directamente contra él y por el valor completo de la pena, y el demandado no podía liberarse con la simple entrega noxal (Cursi, 2002, 218; Albanese, 1967, p. 120)

\section{EL DAMNUM INIURIA DATUM: LA ESTRUC- TURA DEL ILÍCITO Y SU EVOLUCIÓN A TRA- VÉS DE LA INTERPRETATIO PRUDENTIUM}

Individualizado el contenido del plebiscito aquiliano, conviene ahora analizar la estructura del supuesto descrito en los capítulos primero y tercero que, a pesar de las diferencias en su contenido, ha sido generalmente denominado por la doctrina el damnum iniuria datum.

El damnum iniuria datum, de acuerdo con Schipani $(1969$, p. $45 ; 2009$, p. 41), era un supuesto que tenía las siguientes características: (i) En primer lugar, estaba individualizado por cuatro verbos: occidere, frangere, urrere y rumpere; los cuales describían de manera típica tanto la conducta como el evento lesivo que resultaba relevante y que, en todo caso, implicaba un contacto inmediato y material entre el sujeto agente y la cosa dañada; (ii) En segundo lugar, la conducta típica además estaba cualificada por la iniuria, la cual resultaba el criterio que permitía imputar jurídicamente a un comportamiento la respectiva sanción, pues, siendo injustificado el comportamiento del agente era, por lo tanto, reprochable para el derecho; (iii) En tercer lugar, la conducta debía realizarse sobre una cosa ajena, causando su destrucción o deterioro, es decir, que una cosa debía ser matada (animal o esclavo), quemada, hecha pedazos o rota. Por tanto, el evento damnum era también típico $y$, además, estaba cualificado y condicionado por carácter ajeno de la cosa lesionada. Lo cual pone de manifiesto que el objeto de tutela originario de la Lex Aquilia era la propiedad, razón por la cual, la condena consistía, primitivamente, en pagar el valor entero de la cosa a su propietario.

\section{A. La conducta típica: los verba legis}

Los verbos presentes en los capítulos primero y tercero del plebiscito aquiliano precisaban el valor de la genérica expresión damnum faxit (Valditara,

20 Trad.: Y después dispónese, además, que la acción fuese por el duplo contra el que negase (Gai. 7 ad ed. prov. D.9,2,2,1)

21 Trad.: [...] aunque por esta ley se puede ejercitar una acción al doble contra el demandado que niega el hecho (Gai. 3.215).

22 Contra la existencia de esta cláusula procesal en el detalle del texto aquiliano, Talamanca $(2000$, p. 126) indica que la litiscrescenza descendía automáticamente de la fórmula damnas esto presente en los tres capítulos y que por tanto el testimonio de Gayo en sus comentarios al edicto provincial no era el señalamiento al contenido de la lex sino un comentario propio y ello significaba la expresión et infra. En cambio, Corbino formula la hipótesis que de la Lex Aquilia descendían tres acciones una por cada capítulo y que el detalle legislativo era por tanto más detallado y complejo que el reportado por los juristas, en donde al final de cada uno se determinaban los elementos propios de cada supuesto, entre ellos, pero no en todos, una cláusula de litiscrescenza.

23 Ulp. 18 ad ed. D.9,4,2 pr. Si servus sciente domino occidit, in solidum dominum obligat, ipse enim debuit ex maleficio servi in plus teneri, quam ut noxae eum dedat. [Trad.: Si un esclavo mató sabiéndolo su dueño, obliga al dueño por el todo, porque se entiende que el mismo dueño lo mató; pero si ignorándolo, hay la acción noxal, porque por el delito del esclavo no debió quedar obligado a más, que a entregarlo por el dueño.] 
2005, p. 17; 1998, p. 32) ${ }^{24}$ e individualizaban el tipo de conducta relevante para aplicar la sanción, la cual implicaba una actividad física y violenta del agente, que se concretaba en una intervención material y directa de él sobre el objeto lesionado (Schipani, 1969, 48).

Comenzamos por el verbo tipificado en el primer capítulo de la Lex Aquilia: el occidere (matar). Sobre este verbo la jurisprudencia siempre se orientó en una interpretación rigurosamente restrictiva respecto del significado que esta palabra tenía en el lenguaje común, de ello da noticia Juliano en lulianus 86 dig. D.9,2,51 pr. ${ }^{25}$.

En este pasaje Juliano explica que en el lenguaje común occidere significaba procurar la muerte en cualquier modo, pero, para efectos de la Lex Aquilia, significaba solo aquella muerte provocada con la fuerza o con un arma; conectando el verbo a la misma raíz de caedere/caedes (golpear violentamente con las manos o con un arma/golpe con la mano u otro objeto), por lo tanto, hacía referencia a una acción material y violenta procurada sobre el corpus del animal o esclavo (Valditara, 2005, p. 19; Ziliotto, 2000, p. 16). ${ }^{26}$.

La doctrina romanista sostiene que el sentido técnico del verbo correspondía a su significado originario, el cual había sido utilizado anteriormente en las XII Tablas, en donde se identificaba con el verbo caedere y, además, había sido utilizado también en una lex de Numa recorda- da por Festo, donde se contrapuso el occidere al simple necare, siendo el primero aquella muerte ocasionada por un golpe $y$, por tanto, que implicaba una actividad material sobre el corpus de la cosa dañada. En cambio, parece que ya al inicio del siglo II a. C. el uso del verbo occidere se había ampliado para abarcar otras hipótesis de causación de la muerte, no obstante, como Juliano dio noticia, la jurisprudencia siempre se mantuvo ligada a la acepción originaria del verbo (Valditara, 2005, p. 20).

Adicionalmente, el uso del verbo en un sentido restringido en materia aquiliana resulta confirmado porque la técnica jurídica de la época ya conocía formulaciones más generales en lo referente al homicidio, como lo confirma otra antigua lex de Numa sobre homicidio voluntario, la cual disponía si qui hominem liberum dolo sciens morti duit, paricidas esto ${ }^{27}$. En esta disposición se preveían variados modos de causar la muerte -mortem dare-, mientras que la elección del legislador aquiliano fue el uso del preciso verbo occidere que individuaba solo aquella muerte causada directa, física y violentamente (Ziliotto, 2000, p. 17).

Con todo, la jurisprudencia llevó a cabo un proceso de ampliación del ámbito de aplicación del capítulo primero, mediante la interpretación del verbo occidere, por lo menos en lo referente al envenenamiento de un esclavo, de lo cual nos da noticia Ulpiano en Ulp. 18 ad ed. D.9,2,9, pr. $^{28}$.

24 El causar un daño (damnum faxit) era un requisito imprescindible para la configuración del ilícito aquiliano, pues, a pesar de que la expresión sólo se encontraba en el tercer capítulo, estaba implícita en los demás capítulos, ya que no bastaba la simple realización de la conducta, sino que la misma se debía concretar en un evento dañoso y, al mismo tiempo, era relevante sólo el daño ocasionado mediante las conductas tipificadas.

25 Iulianus 58 dig. D.9,2,51 pr. Ita vulneratus est servus, ut eo ictu certum esset moriturum: medio deinde tempore heres istitutus est et postea ab alio ictus decessit : quaero, an cum utroque de occisio lege Aquilia aggi possit. Respondit : occidisse dicitur vulgo quidem, qui mortis causam quolibet modo praebuit : sed lege Aquilia is demum teneri visus est, qui adhibita vi et quasi manu causam mortis praebuisset, tracta videlicet interpretatione vocisa caedendo et a caede... [Trad.: Un esclavo fue herido de tal modo, que se creía cierto que había de morir de aquella herida, después en el tiempo intermedio fue instituido heredero, y herido posteriormente por otro, murió; pregunto ¿por la ley Aquilia se podrá reclamar contra ambos por razón de la muerte? Respondió, que ciertamente se dice por el vulgo, que mató el que de algún modo dio causa para la muerte, pero que por la ley Aquilia se consideró que quedaba obligado solamente el que, habiendo empleado la fuerza, y como por su mano, hubiese dado causa para la muerte, tomando, por supuesto, esta interpretación de la palabra, de caedere y de caedes...]

26 Este sentido técnico que Juliano le atribuyó al verbo occidere, fue confirmado luego por Ulpiano quien, en Ulp. 18 ad ed D.9,2,7,1, hizo un elenco de conductas que armonizan con este significado y ulteriormente el mismo jurista, en el contexto de comentar el Senadoconsulto Silaniano (Ulp. 50 ad ed. D.29,5,1,17), reportó un elenco de conductas que configuraban un occidere realizado por Labeón, coincidentes con el mismo sentido técnico.

27 Trad. libre: Si alguno dio muerte a un hombre libre intencionalmente será un parricida.

28 Ulp. 18 ad ed. D.9,2,9, pr. Item si obstetrix medicamentum dederit et mulier perierit, Labeo distinguit, ut, si quidem suis manibus supposuit, videatur occidisse: sin vero dedit, ut mulier offerret, in factum actionem dandam, quae sententia vera est, magis emim causam mortis praestitit quam occidit. 1. Si quis per vim vel suasum medicamentum alicui infundit vel ore vel clystere vel si eum unxit malo veneno lege Aquilia eum teneri, quemadmodum obstetrix supponens tenetur. [Trad.: Asimismo, si una partera hubiere dado un medicamento, y de resultas hubiere perecido la mujer, Labeón distingue, que si verdaderamente lo aplicó con sus manos, se entenderá que mató, y que si lo dio, para que la mujer se lo aplicase, se ha de dar la acción por el hecho; cuyo dictamen es verdadero, que más bien que mató, dio causa para la muerte. 1. Si por fuerza o persuasión alguno administró a otro un medicamento o por la boca o con lavativa, o si lo untó con un veneno malo, queda sujeto a la ley Aquilia, así como queda sujeta la comadrona que lo aplica.] 
El jurista en este fragmento, en primer lugar, nos dio testimonio del caso de una partera que daba un veneno a una mujer esclava, respecto del cual Labeón distinguió: si la partera lo aplicó con sus manos, procedía la acción ex lege Aquilia, en cambio, si lo dio para que la mujer lo aplicara, procedía sólo la tutela in factum, pues no la mató sino que dio causa a su muerte. A esta distinción, Ulpiano prosiguió para darle una proyección general, afirmando que si alguno, mediante el uso de la fuerza o de la persuasión, suministró o aplicó directamente un veneno, quedaba sujeto a la acción directa de la ley Aquilia.

Así, cuanto menos en el caso del suministro de un veneno, si se estaba en presencia de un contacto físico entre el agente y la víctima, no era necesario el uso de la violencia para que se configurara el occidere, pues bastaba tan solo la persuasión. Por lo tanto, de manera más general, podría decirse que el requisito de la violencia implícito en el verbo, en la aplicación práctica de la ley, se esfumó bastando solo el contacto físico (Ziliotto, 2000, p. 148).

La razón de ser de la interpretación restrictiva del verbo occidere por parte de la jurisprudencia, era la naturaleza penal del remedio aquiliano, pues solo podía proceder cuando se había ocasionado la muerte mediante un comportamiento que, con toda certeza, conforme a la experiencia humana, tenía la eficacia para producirlo; sancionando solo aquel damnum que no provenía del periculum natural a que estas cosas estaban expuestas pues, siendo seres vivos, eran susceptibles de sufrir la muerte por causas naturales (Corbino 2005, p. 174; Valditara, p. 2005,21$)^{29}$.

Continuando con los verba legis, la Lex Aquilia en su tercer capítulo previó tres conductas: urrere (quemar) frangere (hacer pedazos) y rumpere (romper) una cosa ajena.

Con relación al verbo urrere, Ulpiano enunció una serie de hipótesis en las cuales la provocación de un incendio se consideraba relevante ex capite tertio (Ulp. 18 ad ed. D.9,2,27,7-12 y Coll. XII,7,1$10)^{30}$. Este elenco se abre con una regla general, según la cual, quien quemaba una casa de alquiler, arboleda o villa ajena quedaba sujeto a la sanción ex lege Aquilia y, además, si el incendio se ocasionaba intencionalmente estaba sujeto también a la pena capital de quasi incendiarius.

Luego, continua Ulpiano relatando aquellos casos en los cuales el fuego no era aplicado a una cosa ajena, pero se propagaba hasta ella, en donde se ponía de relieve más que un problema de tipicidad de la conducta, uno de causalidad directa y, por lo tanto, de conceder la acción directa nacida de la Lex Aquilia o aquella pretoria.

En el caso de quien aplicaba fuego a una casa ajena y el fuego se propagaba a la casa vecina, el jurista, citando a Labeón, afirmó que se concedía la acción directa tanto al propietario de la casa inicialmente quemada, como al propietario de la casa vecina y al propietario de los bienes muebles que se encontraban en ambos lugares (Coll. XII,7,3; UIp. 18 ad ed. D.9,2,27,8; Ziliotto, 2000, 164) ${ }^{31}$. En este último caso, es palmario que no existía una relación directa y material entre la conducta del agente y el evento y, por lo tanto, que era un caso de causalidad mediata; por esta razón, la doctrina ha pensado que para el jurista el dolo inicial permitía superar el obstáculo representado por la falta de inmediatez entre conducta y evento (Ziliotto, 2000, p. 164).

En cambio, cuando se daba fuego a una cosa propia o, en general, de manera lícita y el mismo se extendía a una cosa ajena, la mayor parte de los juristas opinaron que no era procedente la acción directa ex capite tertio (Coll. XII,7,4-6), porque no existía una relación directa entre la conducta del agente y el evento acaecido, pues quien dio fuego a una cosa propia no incendió la cosa ajena, sino tan solo dio causa al incendio. Igual solución se proyectó para el caso de aquel que custodiaba un fuego iniciado por otro $y$, a causa de su negligencia, se quemaba una cosa ajena (Coll. XII,7,7).

Dentro de las conductas sancionadas ex capite tertio, se enocntraba luego el frangere. Este verbo ya había sido usado en las XII Tablas para describir el os fractum (XII Tab 8,3), el cual consistía en causar la fractura de un hueso, siempre que fuera manu fustive (con la mano o un bastón). Esta cualificación del verbo en la legislación decenviral implica-

29 Valditara justifica la interpretación restrictiva del verbo de la ley, además, en el hecho que, bajo el imperio del procedimiento de las acciones de la ley, la actio ex lege aquilia era una acción ejecutiva y, por lo tanto, se requería una alta probabilidad de la efectiva responsabilidad del demandado para promover el proceso.

30 Los fragmentos sobre el tema que se encontraban en el libro XVIII de los Comentarios al edicto de Ulpiano fueron compilados tanto en el Digesto como en la Collatio, sin embargo, en esta última compilación prejustinianea se encuentran reportados de manera más completa, porque en el Digesto se omitieron algunos pasajes de la obra o porque algunos pasajes fueron recortados.

31 Sobre las diversas interpretaciones de este pasaje y las diferencias de la versión compilada en la Collatio y en el Digesto. 
ba, no la causalidad material ya de por sí implícita en la descripción de la conducta, sino la presunción del conocimiento y la conciencia del agente. Por lo que se trataba de la descripción de una conducta típica, de un evento típico (la fractura de un hueso) y cualificado además por una específica modalidad (Bignardi, 1997, p. 18).

En materia aquiliana, de la interpretación de este verbo por obra de la jurisprudencia se encuentran pocos ejemplos en las fuentes, entre ellos, el caso del artesano que hacía pedazos un cáliz ajeno con el cual debía decorar; y el que destrozaba las puertas de un edificio ajeno (Ulp. 18 ad ed. D.9,2,27,2931). Estos ejemplos permiten concluir que el legislador adoptó el mismo sentido que el verbo tenía en la disposición decenviral, es decir, el de hacer pedazos una cosa mediante una conducta realizada directamente sobre el corpus del objeto (Bignardi, 1997, 38).

Conviene ahora ocuparse del último verbo: el rumpere, que también aparecía en la legislación decenviral, en la XII Tab 8,2 que sancionaba el membrum ruptum. La norma decenviral individuaba cualquier conducta violenta que causara la lesión a una parte del cuerpo, limitando o anulando la funcionalidad de un miembro de manera permanente. Dado que, a diferencia del os fractum, el legislador decenviral no cualificó esta conducta, se punía cualquiera que causara el evento lesivo, lo cual parece confirmado por Gellio quien afirmó que el membrum ruptum encontró aplicación también cuando el agente no había actuado intencionalmente (Bignardi, 1997, p. 19).
En materia aquiliana, la interpretación de este verbo adelantada por la jurisprudencia republicana, a diferencia de lo ocurrido con el occidere, fue en un sentido bastante amplio, de lo cual da noticia Ulpiano afirmando que ya los veteres entendían el verbo rumpere en el sentido de corrumpere (corromper) ${ }^{32}$.

Las fuentes permiten asegurar que la apertura a una interpretación extensiva del verbo se evidencia desde los fundadores del ius civile, dado que fue sobre este preciso tema que se dio el primer fragmento de Bruto que comentaba la Lex Aquilia el cual constituye un seguro terminus ante quem para la datación de nuestra ley.

Bruto afirmó que, si alguno golpeaba una esclava o una yegua y por ello abortó, aquel quedaba sujeto a la Lex Aquilia, pues era como si lo hubiere roto (Bignardi, 997, 44; Cannata, 1995c, p. 133) $)^{33}$. Se observa de inmediato que el comentario se refiere a los bienes que eran objeto de tutela ex capite primo, pero, en este caso, hacía alusión a la tutela ex capite tertio por un daño no destructivo a un animal, lo cual, desde ya, permite evidenciar la tendencia amplificadora de la tutela aquiliana por parte del jurista republicano.

Con relación a la interpretación de esta opinión de Bruto, encontramos dos grandes orientaciones: aquellos que, como Cannata (1995c, p. 133; 1995a, p. 46) $)^{34}$, creen que el jurista entendía que el bien lesionado era la esclava o la yegua; y aquellos que, como Bignardi (1997, p. 31) $)^{35}$, afirman que la lesión recaía directamente sobre el feto, entendi-

32 Ulp. 18 ad ed. D.9,2,27,13. Inquit lex 'ruperit'. Rupisse verbum fere omnes veteres sic intellexerunt 'corruperit'. [Trad.: Dice la ley: 'hubiere roto'; y casi todos los antiguos entendieron así el verbo haber roto, 'hubiere corrompido']

33 Ulp. 18 ad ed. D.9,2,27,22. Si mulier pugno vel equa ictu a te percussa eiecerit, Brutus ait Aquilia teneri quasi ruptio $<$ fetu>. [Si golpeada por ti una mujer con el puño, o una yegua con otro objeto, hubiere malparido, dice Bruto, que te obligas por la ley Aquilia, como si hubieras roto <al feto>]. La agregación de la palabra fetu al final del fragmento aparece en un escolio en Bas.60,3,27 y en la versión del Digesto Milanés.

34 Afirma el autor, siguiendo una compleja argumentación, en primer lugar, que los fragmentos de UIp. XVIII ad ed. D.9,2,27,22-23 deben leerse como una sola frase, en la cual se citan dos pareceres de Bruto, el primero, el caso del aborto de la yegua causado por un golpe (que era igualmente aplicable a la esclava) y, el segundo, de un mulo que se rompe un miembro por haber sido sobrecargado. En segundo lugar, que según el razonamiento del jurista, un aborto no era un occidere y, por tanto, no era aplicable la tutela ex capite primo; pero el capítulo tercero tampoco podía ser aplicado a la yegua pues esta no era objeto del ceterae res, y porque la yegua en sí misma no fue objeto de un rumpere, sino lo fue el feto (y por tanto es innegable que se debe agregar esta locución 'fetu'). Por tanto, afirma el autor, que quien había golpeado a una yegua y había causado la ruptio del feto era sancionado ex capite tertio por haber quasi ruptio fetu. Continua el autor, afirmando que Bruto pretendió con el primer caso abrir la justificación para la solución propuesta en el segundo caso y, así, el jurista individualizó en el feto y en el miembro del animal, la cosa que fue rota, pero, por ser parte integrante del mismo cuerpo, debía tenerse en cuenta al animal y su valor para efectos de calcular la condena. Por lo que se trató de dos casos de daño de una pecus que fueron ingresados a la tutela ex capite tertio analizando, por un lado, una ruptio a un miembro de la pecus considerado en sí mismo para efectos de la determinación de hecho dañoso y, por otro lado, como parte del animal para la valoración del daño.

35 La autora, luego de criticar la posición de Cannata, afirma que, de Ulp. 17 ad Sab. D.7,1,68 pr., se deduce que Bruto había afrontado ya el problema del feto de un animal o esclava y el jurista consideraba el feto como un bien futuro. Luego, bajo un análisis de la formación sintáctica de la frase de de Bruto en Ulp. 18 ad ed. D.9,2,27,22, concluye que el evento quasi ruptio fetu estaba ligado directamente a la responsabilidad (teneri) y, en cambio, la conducta violenta que causó el aborto sólo era una condición para la producción del evento lesivo; y se trataba de un quasi ruptum, por cuanto, se refería a un bien peculiar, pues, siendo el feto una cosa futura, podía considerarse sólo como un bien patrimonial 
do como un bien futuro que es parte del patrimonio del dominus.

La interpretación según la cual el objeto lesionado era el feto llevaría a concluir que, en realidad, el jurista republicano no pretendió abrir la posibilidad del remedio aquiliano ex capite tertio para los daños no destructivos y, por tanto, no tuvo influencia en la posterior ampliación del ámbito de aplicación del verbo rumpere, hasta abarcar cualquier tipo de mutatio in peius de la cosa (Bignardi, 1997, p. 48) ${ }^{36}$.

En cambio, quienes consideran que la pecus era el bien lesionado, sea directa o indirectamente, encuentran en esta solución el inicio del camino que los juristas sucesores a los fundadores continuarían, que consistió en conceder la posibilidad de accionar ex capite tertio por los daños no destructivos sufridos por un esclavo o pecus y, más en general, la ampliación del remedio aquiliano a cualquier tipo de deterioro de una cosa material ajena, lo cual, sólo era posible mediante el entendimiento del verbo rumpere en el sentido más amplio de corrumpere, que abarcaba todo tipo de deterioro material de la cosa.

La regla resultó ser totalmente adquirida por Quinto Mucio Scævola (Pomp. 17 ad Q. M. D.9,2,39 pr.), jurista republicano de la generación sucesiva a los fundadores, quien no dudó en calificar la conducta que causaba el aborto de una yegua como un rumpere. La interpretación del verbo en este sentido encontró su plena aplicación en jurisprudencia clásica, de lo cual dio noticia Gayo, afirmando que las cosas objeto de tutela ex capite primo lo eran también respecto del capítulo tercero, cuando se trataba de daños no destructivos (Gai. 3.217), y Ulpiano que, como se vio, al reportar el contenido del capítulo tercero del plebiscito, agregó la aclaración praeter et hominem pecudinem occisos (Cannata 1995 a, p. 47 ; 1995c, p. 137; Valditara, 2005, p. 27; Corbino, 2005, p. 77).

Habiéndose ocupado los veteres de ampliar la comprensión del verbo en el sentido de corrumpere, la jurisprudencia clásica se ocupó de delimitar el ámbito de aplicación de este. Así, Ulpiano en Ulp. 18 ad ed. D.9,2,27,14-16, reportando el parecer de Celso, evidenció el ámbito omnicomprensivo que tenía el verbo ya en la época de este jurista, incluyendo los verbos urrere y frangere. Luego, el mismo Ulpiano, ofreció una suerte de definición de rumpere, según la cual: se tenía que alguno había roto cuando había herido o golpeado con otro objeto, de suerte que hubiera dañado el cuerpo (Ulp. 18 ad ed. D.9,2,27,17).

Pese a la amplitud con la que los juristas interpretaron el verbo, siempre se requirió, para la aplicación del remedio aquiliano directo, una conducta inmediata y material del agente, ya fuera cometida con su propio cuerpo o con el uso de un instrumento, y sobre el cuerpo mismo de la cosa, la cual ocasionara una alteración o, cuanto menos, una violación a la sustancia del objeto físico, es decir, una mutatio rei (Valditara, 2005, p. 28).

Coherente con esta definición, resultaba excluido de la tutela aquiliana directa ex capite tertio aquellas conductas que no implicaban un contacto directo del agente con la cosa corrompida (Gai. 3,219); así como los daños ocasionados por una omisión (Coll. XII,7,7.); la simple dispersión o pedida de los bienes (Alf. 3 dig. D.19,5,23; Ulp. 11 ad ed. D.4,3,7,7); y el simple consumo de bienes que son por su naturaleza consumibles (Ulp. 18 ad ed. D.9,2,30,2).

\section{B. El nexo de causalidad: el principio damnum corpore suo datum}

Los verbos típicos de la Lex Aquilia expresaban no sólo la conducta que era relevante sino también, implícitamente, las características del nexo causal requerido entre el comportamiento del agente y el evento lesivo. En este sentido, según la lectura de la doctrina romanista mayoritaria, el daño debía ocasionarse mediante un contacto material, directo y físico del agente con la cosa; es decir, que el daño pudiera vincularse directamente a un esfuerzo muscular, esto es, que fuera corpore suo datum (Albanese, 1950, p. 180; Schipani, 1969, p. 46; Valditara, 2005, p. 31).

A pesar de que el principio del damnum corpore suo datum o de la causalidad material no se encontraba dentro del texto legislativo de manera explícita, el mismo fue formulado por la jurisprudencia tardorepublicana como resultado de la interpretación misma de los verbos legislativos, en especial,

potencial. En este sentido, concluye la autora que la solución reportada por Bruto consistía en que aquel que había golpeado a una yegua al punto de hacerla abortar (conducta) y, causando en tal modo la muerte del feto (evento y el feto como bien objeto de tutela), había cometido un rumpere en el evento y, por esta razón, estaba sujeto a la sanción ex capite tertio.

36 Según Bignardi, la verdadera innovación propuesta por Bruto, no fue ampliar la tutela ex capite tertio, sino desligar la tipicidad de la conducta para apoyarla exclusivamente sobre el evento, por tanto, el rumpere se ligó al damum (muerte del feto) y la conducta (el golpe al animal) sería cualificada sólo por haber producido tal evento (el aborto que produjo la muerte del feto). 
respecto del occidere, que fue relacionado desde época antigua con caedere (Bignardi, 1997, 48; $2000,501)^{37}$. Este principio solo fue enunciado expresamente por Gayo en su texto Institucional ${ }^{38}$, utilizando por primera vez la expresión damnum corpore suo datum; y luego fue formulado por UIpiano en materia de actio de pauperie ${ }^{39}$.

En época postclásica el principio fue reiterado en las Istitutas de Justiniano, donde, luego de parafrasear el pasaje gayano, incluyó además la mención del requisito del damnum corpori datum, es decir, la necesidad de que la conducta corpore suo del agente fuera, al mismo tiempo, ejercida directamente sobre el cuerpo de la cosa dañada (Bignardi, 2000, 493; Valditara, 1998, 16; Piro, $2004,55)^{40}$.
En el caso de intervención de un tercero en el curso causal, haciendo referencia al caso de aquel que hería mortalmente a un esclavo y que luego otro le propiciaba una segunda herida la cual le causaba inmediatamente la muerte; Celso, Marcelo y UIpiano se inclinaron por negar la procedencia de la tutela aquiliana por occidere respecto del primer sujeto, quien sólo respondía por haberlo herido, mientras el segundo sí respondía por un occidere ${ }^{41}$.

En cambio Juliano, respecto del mismo supuesto, afirmó que ambos resultaban responsables por el occidere $^{42}$. A pesar de que resulte evidente la extensión del nexo causal por parte de Juliano, en todo caso, está implícito en el pensamiento del jurista la necesidad de que el evento sea objetivamente conducible a la conducta del agente, pues

37 Bignardi afirma que, siendo este principio un obstáculo o límite a la aplicación del remedio aquiliano, no se debe considerar que se trató de un criterio formulado exclusivamente por la jurisprudencia, pues habría sido un límite autoimpuesto e insuperable. Sino más bien consistió en la necesidad de mantenerse fiel a un principio establecido por la misma ley y deducible de la interpretación de los verga legis.

38 Gai.3,219. Ceterum placuit ita demum ex ista lege actionem ese, si quis corpore suo damnum dederit, ideoque alio modo damno dato utiles actiones dantur, velut si quis alienum hominem aut pecudem incluserit et fame necaverit, aut iumentum tam vehementer egerit, ut rumperetur; item si quis alieno servo persuaserit, ut in arborem ascenderet vel in puteum descenderet, et is, si ascendendo aut descendendo ceciderit, aut mortuus fuerit aut aliqua parte corporis laesussit. Sed si quis alienum servum de ponte aut ripa in flume proiecerit et is suffocatus fuerit, hic quoque corpore suo damnum dedisse eo quod proiecerit, non difficiliter intellegi potest. [Trad.: Se ha admitido que en virtud de esta ley la acción se puede ejercitar sólo si alguien causa daño directamente con su propio cuerpo, y por esto, para un daño causado de otro modo se conceden acciones útiles como, por ejemplo, si alguien encierra y deja morir de hambre a un esclavo o de una cabeza de ganado que son de otro, o si persuade a un esclavo ajeno para que suba a un árbol o baje a un pozo, y éste, subiendo o bajando, se cae y se mata o lesiona alguna parte del cuerpo. Por el contrario, se puede entender fácilmente que, si alguien arroja a un esclavo ajeno desde un puente o desde la orilla al rio, y éste perece ahogado, aquí también se ha causado un daño con el propio cuerpo a aquel a quien se empujó]

39 Ulp. 18 ad ed. D.9,1,1,7. Et generaliter haec actio locum habet, quotiens contranaturam fera mota pauperiem dedit: ideoque si equus dolore concitatus calce peterit, cessare istam actionem, sed eum, qui equum percusserit aut vulneraverit, in factum magis quam lege Aquilia teneri, utique ideo, quia non ipse suo corpore damnum dedit. At si, cum equum permulsisset quis vel palpatus esset, calce eum percusserit, erit actioni locus. [Trad.: Y en general, tiene lugar esta acción <la actio de pauperies>, siempre que la bestia causó el daño movida contra su naturaleza. Y por tanto, si excitado el caballo con un dolor hubiere dado una coz, cesa esta acción; pero aquel que hubiere golpeado o herido al caballo, queda obligado por la acción del hecho más bien que por la ley Aquilia, y esto así, porque él no causó el daño con su propio cuerpo. Mas si cuando alguno hubiese acariciado o pasado la mano a un caballo, éste le hubiere dado una coz, habrá lugar a la acción.]

40 Sobre este principio, al cual solo hace referencia Justiniano en su texto institucional, Bignardi afirma que el damnum corpori datum respondió, a diferencia del corpore suo, a la necesidad de concretar el concepto mismo de damnum, como límite a la ampliación que la jurisprudencia había hecho al tutelar los daños no destructivos, imponiendo en todo caso el requisito de un contacto directo sobre la cosa y, con ello, la materialidad misma del daño. En cambio, otros como Valditara han afirmado que el principio surgió de la interpretación de la Glosa y no estaba presente en el pensamiento de los juristas romanos, por lo menos no de manera expresa, aunque si se evidencia implícitamente en las fuentes la necesidad de una mutatio res. Esta interpretación por parte de la Glosa, según Piro, se produjo por una errónea lectura de la paráfrasis que Teófilo hizo del pasaje institucional, lo cual resulta probable, además, por la total ausencia del principio en fuentes clásicas.

41 Ulp. 18 ad ed. D.9,2,11,3. Celsus scribit, si alius mortifero vulnere percusserit, alius postea exanimaverit, priorem quidem non teneri quasi occiderit, sed quasi vulneraverit, quia ex alio vulnere periit, posteriorem teneri, quia occidit. Quod et Marcelo videtur et est probabilius. [Trad.: Escribe Celso, que si uno hubiere causado una herida mortal, y después otro hubiere rematado, el primero no queda ciertamente obligado como si hubiere matado, sino como habiendo herido, porque agredido pereció por la otra herida; y que el segundo queda obligado, porque mató; lo que también a Marcelo le parece bien, y es más probable.]

42 Iulianus 86 dig. D.9,2,51 pr.... Rursus Aquilia lege tenerit existimati sunt non solidum qui tra vulnerassent, ut confestim vita privarent, sed etiam hi, quorum ex vulnere certum esset aliquem vita excessurum. Igitur si quis servo mortiferum vulnus inflixerit eundemque alius ex intervallo ita percusserit, ut maturius interficeretur, quam ex priore vulnere moriturus fuerat, statuendum est utrumque eorum lege Aquilia tenerit. [Trad.: También se juzgó que quedan obligados por la ley Aquilia, no solo aquellos que hicieron de tal modo, que inmediatamente privaron a uno de la vida, sino también aquellos por cuyas heridas hubiese la certeza de que alguien dejara vivir, Así, pues, si alguno hecho a un esclavo una herida mortal, y en este intervalo otro le hubiere herido de tal modo, que fuese muerto más pronto de lo que habría de morir por la primera herida, se ha de determinar, que uno y otro quedan obligados por la ley Aquilia.] 
en todo caso, la primera herida por sí sola debía ser suficiente para causar la muerte, por lo que su opinión parece condicionada más por exigencias de política criminal (Valditara, 2005, p. 32).

Al respecto, Piro (2004, p. 38, p. 210 ) en un completo y profundo estudio acerca de este principio y cuya tesis es compartida por Corbino (2005, p. 96), pone de relieve con argumentos no de poca monta, el posible error en la comprensión del damnum corpore suo datum por parte de la doctrina romanista moderna. En especial pone en duda, por un lado, que el requisito de una causalidad material proviniera de la interpretación jurisprudencial de los verba legis y, por otro lado, que el principio damnum corpore suo datum expresara un contacto material, directo e inmediato del agente con la cosa lesionada ${ }^{43}$.

La autora concluye, luego de un exhaustivo examen de las fuentes tanto republicanas como clásicas, que la formulación del principio pudo ser un tentativo de la jurisprudencia de formalizar el principio de causación cierta y directa del daño, a través de la elección de precisas expresiones que describían de la manera más eficaz la intención de salvaguarda del principio, frente a la preocupación de que se produjera una interpretación demasiado extensiva, como el que había intentado Juliano ${ }^{44}$.

Al respecto formula como hipótesis que, de la possesio fue tomada la expresión pues corpore en este ámbito ya había madurado en la praxis jurisprudencial, lo cual permitía, no sólo sintetizar eficazmente el concepto, sino además resultaba absolutamente idónea (Piro, 2004, p. 427).

En conclusión, el uso del ablativo corpore no habría servido para limitar la causalidad a una rela- ción corporal inmediata entre el sujeto agente y la cosa, sino más bien, a un fenómeno más amplio: la verificación de la 'objetiva' idoneidad y directa relación del hecho con el sujeto, en cuanto estaba ligado a un 'comportamiento cierto' de él. Por tanto, la enunciación del principio por la jurisprudencia clásica revelaba su intención de limitar en modo inequívoco el radio de acción de la responsabilidad aquiliana, para que sólo procediera cuando el daño derivaba de un comportamiento estricta e inequívocamente imputable al agente $y$, era esto, lo que los juristas romanos entendían por un daño corpore suo datum (Piro, 2004, p. 429; Corbino, 2005, p. 108).

\section{La iniuria: la antijuridicidad de la conducta}

El primer dato que las fuentes permiten confirmar acerca de la iniuria (Sanchez, 2016) ${ }^{45}$ es la función que cumplía dentro de la estructura del ilícito aquiliano, pues la ley condicionaba la aplicación de la sanción pecuniaria a que la destrucción o deterioro del bien proviniera de un occidere iniuria en el caso del primer capítulo, o de un urrere, frangere rumpere iniuria en el tercer capítulo. Por lo tanto, el uso de la palabra iniuria como ablativo de modo en el texto legislativo se refería a la forma en la cual debía ser provocado el daño, es decir, que cualificaba el comportamiento previsto por el legislador mediante los verba legis (Cannata, 1995b, p. 110).

Lo anterior no sólo resulta del análisis sintáctico del texto plebiscitario, sino además de un argumento dogmático: la destrucción o deterioro de una cosa ajena era per se una situación contraria al ius, pues constituía la lesión al derecho de propiedad de otro, por lo que la iniuria solo podría tener la función de cualificar la conducta (Schipani, 1969, p. 89).

43 La autora manifiesta, por un lado, la inexistencia de fuentes que demuestren la enunciación del principio por parte de la jurisprudencia y que el mismo provino de la interpretación de los verba legis. Por otro lado, pone de presente que el principio sólo fue enunciado por dos fuentes, una de ellas de Ulpiano, la cual ni siquiera se encuentra incluida en la Compilación justinianea dentro del estudio de la Lex Aquilia. De la interpretación de las fuentes que afirman el principio (Gai. 3,219 y Ulp. 18 ad ed. D.9,1,1,7), releva la autora que el principio no expresaba, como unánimemente la doctrina lo afirma, la necesidad de un contacto físico material y directo entre el sujeto agente y la cosa lesionada. En efecto, el único ejemplo que Gayo en su texto institucional reportó de un daño corpore suo, es un caso que no presenta una inmediatez material (aquel que empujó a un esclavo al rio y la muerte se ocasionó por el golpe de la caída más no directa y materialmente por la conducta del agente) y, tratándose de un manual en donde el jurista prefería elegir los ejemplos más significativos, debe dudarse que se tratase de un caso limite o respecto del cual existía duda. Iguales argumentos emplea la autora para referirse al pasaje de Ulpiano, en el cual la fattispecie misma no permite deducir que se tratase de un caso de contacto material e ininterrumpido entre el agente y la cosa lesionada.

44 Evidencia la autora que con Juliano, refiriéndose a su parecer en el caso de concurrencia de varios sujetos en la causación del daño, se verificó una variación en la indagación del nexo causal yendo más allá del límite ofrecido por la experiencia, para imputar un daño aquiliano con la simple 'idoneidad objetiva' del comportamiento para producirlo; $y$, posiblemente, fue esta operación julianea que pudo haber suscitado en la jurisprudencia sucesiva, la necesidad de una formulación expresa del criterio damnum corpore suo datum pues, en efecto, el tentativo de Juliano no fue seguido por los juristas sucesivos.

45 El concepto de iniuria y el surgimiento del concepto de culpa en materia aquiliana, tuvimos la oportunidad de analizarlo en un escrito anterior, así como su evolución a través de la historia del derecho privado, con un particular énfasis en el derecho civil colombiano. Cfr. cuanto hemos expresado en: Sánchez (2016). 
Teniendo claridad acerca de la función de la iniuria dentro de la estructura del ilícito, nos permitimos analizar sucintamente el significado que ella tenía dentro de la regulación de la Lex Aquilia. Ulpiano abriendo el libro 18 de sus Comentarios al edicto, luego de reportar el contenido del primer capítulo, afrontó la discusión acerca del significado iniuria (D.9,2,3-5; Coll. VII,3,1-4), dentro de estos fragmentos resulta particularmente significativo aquel reportado en Ulp. 18 ad ed. D. 9,2,5,146.

En este pasaje ulpianeo el jurista ofreció una especie de definición de iniuria, la cual, si bien es evidente que está influenciada por la evolución interpretativa que este instituto sufrió en lo que se refiere a su estrecha relación con la culpa, es también cierto que, como lo afirma la doctrina romanista, la misma contiene indicios de lo que originariamente significaba el ablativo iniuria en el texto aquiliano.

El jurista afirmó que iniuria en materia aquiliana no debía entenderse como en la actio iniuriarum en el sentido de cualquier ofensa, sino como aquello que se hizo non iure, esto es contra contra ius, es decir, si alguien hubiera matado con culpa. Luego, hizo referencia a la posibilidad de que concurrieran las acciones de la Lex Aquilia y la iniuriarum y, concluyó, afirmando que iniuria se entendía como el daño causado con culpa aún por aquel que no quiso matar.

La doctrina romanista mayoritaria desde el siglo XIX hasta la más contemporánea, ha entendido que la iniuria originariamente en el plebiscito aquiliano tenía el valor de una particular injusticia de la conducta, entendida como la ausencia de una causa justificada por el ius, con presidencia de cualquier valoración subjetiva del comportamiento. En este sentido, en la interpretación de la noticia ulpianea a la que nos referimos, se ha dado un lugar protagónico a la parte del fragmento en la cual se afirma que iniuria era quod non iure factum est, hoc est contra ius ${ }^{47}$ (Schipani, 1969, p. 83; Cannata, 1995a, p. 35; Valditara, 2005, p. 33; 2009, p. 131; Ziliotto, 2000, p. 39).

Lo anterior se justifica en las siguientes razones. En primer lugar, por el contexto en el cual se encuentra el fragmento dentro del discurso ulpianeo, pues hace parte de una secuencia orgánica que, a través de la casuística, permite deducir este significado de iniuria (Schipani, 1969, p. 270). Esta casuística expresa que el problema de la iniuria giró en torno a la existencia o no de una causal de justificación de la conducta, por cuanto los fragmentos anteriores se refieren a la legitima defensa en caso de furtum (Ulp. 18 ad ed. D.9,2,5 pr.; Coll. VII,3,13), y en los posteriores el jurista afrontó el caso de la responsabilidad ex lege Aquilia del incapaz (UIp. 18 ad ed. D.9,2,5,2) y el caso de un docente que causaba un daño a su alumno en ejercicio de su poder contractual de disciplinarlo (Ulp. 18 ad ed. D.9,2,5,2).

En segundo lugar, sobre el contenido mismo del fragmento, la primera parte ha sido considerada genuina, ya que fue reportado de manera homogénea en la versión de la Collatio (Ulp. 18 ad ed. Coll. VII, 3,4) y en un fragmento de Ulpiano donde, con ocasión de la actio iniuriarum, se refirió a la iniuria (Ulp. 56 ad ed. D.47,10,1 pr.) $)^{48}$. Pero, a diferencia de este último fragmento, en el pasaje de UIp. 18 ad ed. D.9,2,5,1 ahora analizado, la definición de iniuria como aquello que no se realizaba en modo justificado, estaba estricta y directamente ligada al texto aquiliano, pues estaba iluminada precisamente por la previa referencia a la legitima defensa, además fue contrapuesta al diverso significado, en sentido de contumelia, que asumía la palabra en el delito de iniuria, y fue complementada con la referencia a los actos contra ius (Cannata, 1995a, 37); con lo cual el jurista pretendió expresar la antijuridicidad del compor-

$46 \quad$ Ulp. 18 ad ed. D.9,2,5,1. 'Iniuriam autem hic accipere nos oportet non quemadmodum circa iniuriarum actionem contumeliam quandam, sed quod non iure factum est, hoc est contra ius, id est si culpa quis occiderit: et ideo interdum utraque actio concurrit et legis Aquiliae et iniuriarum, sed duae erunt aestimationes, alia damni, alia contumeliae. Igitur iniuriam hic damnum accipiemus culpa datum etiam ab eo, qui nocere noluit'. [Trad.: Pero conviene que la iniuria la entendamos aquí, no como respecto a la acción iniuriarum, cualquiera contumelia, sino lo que se hizo no según el derecho, esto es, contra el derecho, a saber, si culpablemente hubiere alguno matado, y por esto concurren a veces ambas acciones, la de la ley Aquilia y la iniuriarum; pero habrá dos estimaciones, una la del daño, y otra la de la contumelia. Así, pues, entendemos aquí por iniuria el daño causado con culpa, aun por aquel que no quiso causarlo].

47 Trad.: lo que se hizo no según el derecho, esto es, contra el derecho.

48 Ulp. 56 ad ed. D.47,10,1 pr. Iniuria ex eo dicta est, quod non iure fiat; omne enim quod non iure fit, iniuria fieri dicitur. Hoc heneraliter; specialiter autem iniuria dicitur contumelia. Interdum iniuriae apellatione damnum culpa datum significatur, ut in lege Aquilia dicere solemus. Interdum iniquitatem iniuriam dicemus; nam quum quis inique vel iniuste sententiam dixit, iniuriam ex eo dictam, quod iure et iustitia caret, quasi non iuram; contumeliam autem a contemnendo. [Trad.: se dijo iniuria por esto, porque no se hace con derecho; porque todo lo que no se hace con derecho, se dice que se hace con iniuria. Esto es en general; pero en especial, la iniuria se llama contumelia. A veces con la denominación de iniuriae se significa el daño causado con culpa, como lo solemos decir en la ley Aquilia. Otras veces llamaremos iniuriae a la injusticia; porque cuando alguno pronunció sentencia inicua o injustamente, se llama iniuriam, porque carece de derecho y de justicia, como si fuera non iuram [no conforme a derecho]; pero contumelia, de contumere.] 
tamiento que implicaba dicha definición (Schipani, 1969, p. 303) ${ }^{49}$.

Luego, cuando Ulpiano afirmó id es si culpa quis occiderit, enlazando la definición de iniuria como non iure a la culpa, pretendió dar noticia del hecho que la culpa apareció para cualificar una conducta como reprochable y, por lo tanto, enganchó la ilicitud expresada en la iniuria a la reprochabilidad subjetiva expresada por la culpa. Lo anterior implicó el acoplamiento entre el momento inicialmente objetivo y posteriormente también subjetivo de la imputación del ilícito, y dio origen a los problemas de los cuales el jurista se ocupó en los fragmentos sucesivos (Schipani, 1969, p. 305).

Adicionalmente, ha sostenido la doctrina que, dado el formalismo interpretativo que dominaba la época de la aprobación del texto legislativo, la elección del legislador de evitar toda referencia al dolo en el texto y, en cambio, preferir la expresión iniuria en el primer y tercer capítulo, fue claramente una elección voluntaria, sobre todo si se tiene en cuenta que en el segundo capítulo se hizo una referencia específica al fraudem, que es una particular forma de dolo, como cualificador de la conducta (Cannata, 1995a, p. 35).

Por lo tanto, de este fragmento se deduce que la definición de iniuria como aquel acto non iure, correspondía, sin duda, a la idea del legislador. En este sentido, el criterio que permitía sancionar los comportamientos previstos en el primer y tercer capítulo aquiliano era su ilicitud, la cual no se refería al daño sino a la conducta y, en especial, a la ausencia de una justificación conforme a los principios del ordenamiento. En cambio, la segunda explicación de Ulpiano: id est si culpa quis occiderit, es la noticia que el jurista ofreció de la reflexión de la jurisprudencia republicana, la cual, como se verá, transpuso el problema de la iniuria en términos de culpa, haciendo descender la culpa del mismo concepto originario de ilicitud previsto en el texto aquiliano (Cannata, 1995a, p. 39).

Por otro lado, existen otros argumentos que la doctrina ha avanzado para atribuirle a la iniuria el valor objetivo de antijuridicidad, los cuales resultan por demás convincentes.

Estos argumentos son: en primer lugar, la ausencia de una explícita referencia al dolo u otro perfil subjetivo de culpabilidad en el primer capítulo de la Lex Aquilia, aun cuando ya en una antigua ley de Numa sobre el homicidio de un hombre libre se distinguía entre aquel homicidio causado dolo sciens o imprudens. Lo cual permite concluir que en la época de la promulgación del plebiscito aquiliano estos conceptos, al menos con relación a la muerte de un hombre, ya eran conocidos por la ciencia jurídica y, dado el formalismo interpretativo reinante en dicha época, si este hubiera sido el querer del legislador lo habría manifestado expresamente (Valditara, 2009, p. 131).

En segundo lugar, en la valoración de la iniuria por parte de los juristas, cuando caso a caso afrontaron la aplicación del remedio aquiliano, es notorio que la reflexión giraba en torno al carácter injusto de la conducta, en especial, a la existencia o no de una causa que justificara el comportamiento conforme al derecho y, como a continuación se verá, fue en este especifico contexto en el cual la jurisprudencia tardorepublicana dio origen al concepto de culpa, el cual emergió como un límite a la estricta aplicación de dichas causas justificativas (Schipani, 1969, p. 133; Corbino, 2005, p. 120; Cursi, 2002, p. 279; Valditara, 2009, p. 135).

En tercer lugar, si originariamente hubiere existido una concepción subjetiva del criterio de responsabilidad, no habría sido necesario acudir a la estricta aplicación del principio de la materialidad de la conducta. Pues la necesidad de que el daño fuera corpore datum, a la par con la ausencia de una causa de justificación, resultaba el modo objetivo de imputación del daño aquiliano y era del todo coherente con el contexto en el cual se produjo la ley, tanto respecto del régimen decenviral precedente, como del régimen negocial de la época, caracterizado por una estricta formalidad (Valditara, 2009, p. 137).

No es casual que, cuando la interpretación de la iniuria comenzó a adoptar un perfil subjetivo mediante la introducción del concepto de culpa, la aplicación del principio danmum corpore suo datum dejó de ser tan estricta (Ziliotto, 2000, pp. 46148). Lo cual permite confirmar la íntima relación entre el carácter objetivo de la iniuria y la exigencia de una rígida aplicación del principio de la causalidad material.

Así, la iniuria, como elemento que cualificaba la conducta en el plebiscito aquiliano, implicaba, al menos en su origen, una particular injusticia del comportamiento, consistente en la ausencia de una causa que lo justificara frente al ius. Por lo que

49 Afirma Schipani (1969, p. 303) que la definición de Ulpiano en este fragmento resulta reconducible al ámbito aquiliano además por el uso de la expresión hic accipere nos oportet que expresa que lo dicho es propuesto para los fines de un ámbito particular, ámbito que sin duda el del texto aquiliano. 
conviene a continuación ocuparnos de cómo en el seno de la aplicación de estas causales de justificación surgió tempranamente en la jurisprudencia el concepto de culpa.

\section{D. (Sigue) La reinterpretación de la iniuria y la emersión de la culpa}

Desde época tardorrepublicana los prudentes, en el ámbito de la interpretación y aplicación de la Lex Aquilia, se encargaron de precisar el concepto de iniuria con una notable amplitud, pasando de una consideración puramente objetiva propia del texto legislativo originario, a dar relevancia al carácter subjetivo del comportamiento mediante el concepto de culpa.

En este sentido se encuentran algunos fragmentos que reportan el pensamiento de juristas de esta época, en los cuales, por un lado, resulta evidente la apreciación de la iniuria en clave de antijuridicidad objetiva y, por otro lado, denotan la emersión de la culpa en el seno de su interpretación. De gran importancia resulta un parecer de Q. Mucio Scevola, jurista del siglo I a. C., reportado por Paulo en sus Libri ad Sabinum (Pau. 10 ad Sab. D.9,2,31 ${ }^{50}$ ).

Este fragmento narra el caso de un podador que había dejado caer una rama de árbol en la cabeza de un esclavo transeúnte $y$, como consecuencia de ello, el esclavo murió. A esta hipótesis se insertó la referencia al machinarius (operario que realizaba trabajos en un andamio) que dejaba caer un objeto causando el mismo efecto lesivo, con lo cual se pretendió homologar la solución. Paulo reportó primero la solución de Sabino quien distinguió, para efectos de la procedencia del remedio aquiliano, si los hechos ocurrían en un lugar público o privado, procediendo la accion aquiliana sólo en caso de un lugar público y bajo la condición que el podador no hubiera advertido a voces la inminente caída de una rama ${ }^{51}$.

Al parecer sabiniano le sigue el de Q. Mucio quien razonó en torno a la hipótesis de podado in privato, la cual hacía poner un mayor énfasis en el carácter justificado de la conducta, por cuanto constituía el ejercicio del derecho de dominio y, en este caso, decidió limitar la justificabilidad del comportamiento acudiendo a un criterio del todo diverso: la culpa. Dicho criterio lo concretó afirmando que se actuaba con culpa cuando habiéndose podido proveer por una persona diligente no se proveyó, o se avisó cuando no podía evitarse el peligro, es decir, que no se adoptó aquellas medidas preventivas con el fin de evitar que se verifique un daño (Schipani 1969, p. 140; Voci, 1990, p. 43; Astolfi, 1993, p. 317) $)^{52}$.

Por tanto, según el jurista, resultaba justificada la conducta de aquel que, podando un árbol o trabajando en un andamio, dejaba caer un objeto causando la muerte de un esclavo, siempre que, aun tratándose de un lugar privado, hubiera tomado las medidas que una persona diligente habría tomado para prevenir la ocurrencia del daño, entre ellas, avisar en tiempo la inminente caída de un objeto (Cannata, 1971, 68); Valditara, 2009, 136). Teniendo esta idea presente, por último, Paulo concluyó que tratándose de lugares donde no transitaban personas por ausencia de camino, sólo se respondía por dolo, puesto que no podía adivinarse que alguno pasaría, por ello no se esta-

50 Pau. 10 ad Sab. D.9,2,31. Si putator ex arbore ramum cum deiceret vel machinarius hominem praetereuntem occidit, ita tenetur, si is in publicum decidat nec ille proclamavit, ut casus eius evitari possit. Sed Mucius etiam dixit, si in privato idem accidisset, posse de culpa agi: culpam autem esse, quod cum a diligente provideri poterit, non esset provisum aut tum denuntiatum esset, cum periculum avitari non possit. Secundum quam rationem non multum refert, per publicum an per privatum iter fieret, cum prelumque per privata loca volgo iter fiat. Quod si nullum iter erit, dolum dumtaxat praestare debet, ne immittat in eum, quem viderit transeuntem: nam culpa ab eo exigenda non est, cum divinare non potuerit, an per eum locum aliquis transiturus sit. [Trad.: Si un podador al desprender una rama del árbol, o el que trabajaba sobre un andamio, mató a un hombre que pasaba, es responsable si aquella cayese en sitio público, y el no dio voces para que pudiera evitarse el peligro. Pero también dijo Mucio que, si esto mismo hubiese sucedido en lugar privado, puede reclamarse por la culpa; y que hay culpa, porque habiéndose podido provideri por persona diligente no se proviso, o se avisó cuando no podía evitarse el peligro. Por cuya razón no hay mucha diferencia entre que se pasara por lugar público, o por privado, puesto que muchas veces se pasa por la generalidad por lugares privados. Mas si no hubiere camino alguno, debe responder tan solo del dolo, para que no eche nada sobre aquel que viere que pasaba; porque no se le ha de exigir culpa, cuando no hubiere podido adivinar, si por aquel habría de transitar alguno.]

51 El criterio del carácter público o privado de un lugar para determinar la responsabilidad de quien realizando ciertas actividades causaba un daño, corresponde al pensamiento de Sabino, pues el mismo criterio se encuentra presente en otro fragmento de los libros ad Sabinum de Paulo (Pau. 10 ad Sab. D.9,2,28 pr.) (Astolfi 1993, p. 317). Sin embargo, como justamente anota Cardilli (2014, p. 19) era el deber de advertir la caída de una rama (proclamare), más no el carácter público del lugar, el elemento necesario para darle sentido jurídico y coherencia al parecer de Sabino.

52 Sobre el verbo providere, de central importancia en la definición muciana, este tenía dos diversos e igualmente validos significados en la lengua latina: el de prever y el de proveer, pero el adoptar uno u otro significado da un sentido totalmente diferente a la noticia del jurista. Dentro de la lógica interna del fragmento, resulta con mayor probabilidad que el verbo haya sido usado en el sentido de proveer, es decir de haber realizado todas las medidas necesarias para evitar el daño. Sobre las razones por las cuales se debe considerar que Q. Mucio utilizó el verbo providere en sentido de proveer. 
ba obligado a proveer las medidas necesarias para evitar un daño (Schipani, 1969, p. 371).

Este fragmento, especialmente en lo que refiere al parecer de Q. Mucio, constituyó un progreso enorme en la valoración de la conducta del agente para efectos de. imputar un daño aquiliano, por cuanto, no sólo abrió la puerta a la valoración subjetiva del actuar, sino que dicha valoración, acudiendo a la noción culpa, fue ligada a un modelo de comportamiento ideal, el cual se asumió como valor de referencia para comprar el comportamiento concreto del agente, modelo que consistió en el del homo diligens. Así, la culpa para Q. Mucio representaba, por un lado, el comportamiento que se desviaba de aquel que habría tenido el hombre diligente, pero, por otro lado, y con prescindencia de dicho modelo, implicaba también la valoración de lo que concretamente el agente habría debido hacer para evitar el peligro, introduciendo para este caso concreto el deber de denuntiare (Cardilli, 1995, p. 190; 2014, p. 20).

Encontramos también algunos fragmentos de Alfeno Varo, jurista del siglo I a. C., de los cuales resulta especialmente importante el parecer expresado en el caso del tabernarius (Alf. 2 dig. D.9,2,52,1), en el cual un hombre, presumiblemente esclavo, había sustraído una linterna puesta en una calle por un ventero, percatándose el ventero lo persiguió y lo agarró, y habiendo el esclavo golpeado con un látigo al ventero, se formó una riña en la cual el esclavo resultó lesionado. Por lo cual se preguntó al jurista si el ventero había causado un daño con iniuria y si, en consecuencia, podía el dominus del esclavo accionar contra él.

El jurista razonando en torno a la existencia o no de la iniuria, respondió formulando dos hipótesis diversas: si el esclavo lo había golpeado primero y entonces la lesión no se había causado a propósito (data opera), sino en defensa propia, la conducta no había sido cometida con iniuria porque estaba plenamente justificada en la necesidad de defenderse. En cambio, imaginando el jurista una hipótesis diversa, si la riña había sido iniciada por el ventero, el daño había sido causado por su culpa y por tanto estaba sujeto a la Lex Aquilia.

Resulta interesante también el parecer de Alfeno Varo en Alf. 10 dig. D.9,2,52,4, donde acudió nuevamente a la culpa para valorar el carácter justificado de una conducta lesiva realizada en medio de una actividad deportiva.

Los hechos ocurrieron en medio de un juego de pelota, en donde uno de los jugadores, intentando apoderarse de la pelota, empujó a un esclavo ajeno y lo lesionó; por lo que se preguntó al jurista si el dueño del esclavo podía accionar ex lege Aquilia contra aquel jugador que le había causado la lesión. La valoración del jurista recayó sobre la existencia o no de la iniuria en el comportamiento, especialmente por el contexto en el cual se produjo la lesión: en medio de un juego en el cual empujar a otro jugador podría considerarse una conducta justificada. En este sentido, el jurista respondió negativamente a la procedencia de la acción aquiliana, por cuanto la lesión se produjo casu magis quam culpa (Schipani, 1969, p. 176).

Sin embargo, el jurista se refirió al casus no para excluir la existencia de una relación causal, sino para indicar que la misma no era suficiente para la procedencia del remedio aquiliano, por cuanto no hubo culpa. Descartó la culpa, pues el comportamiento era justificado y no era reprochable, ya que en el desarrollo de una competencia deportiva estaban implícitos ciertos riesgos, como el de ser empujado por un jugador con el fin de obtener la pelota, conducta habitual dada la naturaleza misma de la actividad (Schipani 1969, p. 77; Del CastiIlo, 1994, p. 32).

Como resulta de lo anterior, la valoración de la iniuria por parte de la jurisprudencia giró en torno a la existencia o no de una causa que permitiera justificar el comportamiento lesivo. Así, los juristas razonaron en torno a categorías que hoy conocemos como la legitima defensa, el estado de necesidad, el ejercicio de una actividad lícita y el ejercicio de un derecho; todas circunstancias que permitían enervar la aplicación del remedio aquiliano, por cuanto, a pesar de existir un comportamiento que se subsumía en alguno de los verba legis, el comportamiento estaba justificado frente al derecho $y$, por lo tanto era privo de sanción.

Sin embargo, otro elemento común en los fragmentos analizados es que, siendo justificada la conducta pues estaba presente una circunstancia que permitía considerarla iure, la jurisprudencia impuso ciertos límites a dicho carácter justificado, para lo cual se recurrió al concepto de culpa (Cannata 1995a, p. 40); la cual fue relacionada con ciertos tipos de comportamiento, tales como consulto, non providere, data opera, los cuales tenían un valor meramente descriptivo, que en algunos casos expresaban voluntad o intencionalidad, mientras en otros el no haberse comportado conforme a un modelo ideal de conducta (Schipani, 1969, p. 96).

Por lo tanto, la culpa no constituía en su origen un requisito autónomo para imputar la sanción aquiliana, ni tampoco tenía un unívoco significado; pero tampoco existía en el razonamiento de los juristas un criterio unitario de imputación. En algunos casos, la constatación de los requisitos 
legales y la ausencia de una causa justificativa, independientemente de cualquier juicio de reprobación subjetiva, bastaba para imputar la sanción; mientras que en otros, la voluntad o el modo en que el agente se comportó y su especifica reprochabilidad permitía imputarle el daño, aun cuando hubiere un comportamiento objetivamente permitido o materialmente no hubiere causado el daño (Schipani, 1969, p. 90).

Las reflexiones de jurisprudencia sucesiva, coherente con la labor realizada por los juristas republicanos, se concentraron en la determinación y delimitación de la noción de culpa, cuya introducción a la estructura del ilícito aquiliano ya había sido realizada mediante la interpretación extensiva de la iniuria del texto plebiscitario. En este sentido se evidencia un fragmento de Gayo, jurista del siglo II d.C., de sus Comentarios al edicto provincial $^{53}$.

El principium de este fragmento sin duda fue mutilado por obra de los compiladores, pues comienza diciendo Idem iuris est pero falta la solución precedente cuya regla de derecho valía también para el caso ahora examinado. Sin embargo, la noticia resulta de todo interés porque evidencia la relación que Gayo proyectó entre imperitia y culpa. EI jurista reportó dos casos en los cuales un médico respondía ex lege Aquilia por la muerte su paciente esclavo: cuando había erróneamente usado un medicamento y cuando, luego de haberle realizado una intervención, había descuidado al paciente en los cuidados posoperatorios.

El jurista, comprendiendo la diferencia de los dos supuestos, por cuanto el primero implicaba un error en la ejecución de su actividad, mientras el segundo la omisión de los cuidados necesarios posteriores a una intervención; encontró en ambos casos un elemento común: la culpa. Pues los cuidados posoperatorios no eran una actividad autónoma, sino un acto cronológicamente sucesivo y atado al procedimiento previo, por lo que el derelinquere curationem no constituía en sí mismo el occidere, pero la culpa hacía que el procedimiento quirúrgico en su integridad se considerara realizado con impericia y, por tanto, como causa de la muerte (Schipani, 1969, p. 345).

Así, la intervención del médico sobre el esclavo mediante una actividad que comportaba o podía comportar lesiones era iure, pues el contrato con el dominus se lo consentía; pero, el actuar del médico excedía los límites contractuales y se convertía en ilícito, cuando actuaba con impericia, pues sólo le era consentida una intervención al cuerpo del esclavo realizada conforme a las reglas de su arte (Cannata, 1995b, p. 60).

Luego, el primer párrafo de la noticia de Gayo prevé un caso diverso, el de un carretero que, por impericia o debilidad, no lograba contener el ímpetu de las mulas que arriaba y las mismas atropellaban a un esclavo. A este caso se asimiló aquel que, por impericia o debilidad, no lograba hacer frenar el caballo que cabalgaba. En estos casos el jurista consideró que era imputable el daño aquiliano al carretero/jinete cuando había actuado con culpa, lo cual ocurría no sólo cuando por impericia no logró retener los animales, sino también cuando sabiendo o debiendo saber de su debilidad, asumía la actividad de carretero o equitador que era por su naturaleza peligrosa (Rotondi, 1916, p. 956).

En este fragmento, el jurista tendió a una solución analítica del caso, realizando un planteamiento más general basado los criterios de imperitia (impericia) e infirmitas (debilidad) los cuales condujo al concepto de culpa. Además, guarda lógica con el párrafo anterior respecto al recurso de la impericia y a la relación entre la culpa y la omisión, por cuanto, el análisis no radicó en que el sujeto en el desarrollo de cierta actividad había cometido errores técnicos, sino en que el mismo no estaba preparado para realizar la actividad y no obstante la ejecutó. Oscilando entre una comprensión de la impericia como un comportamiento positivo o, también, como una omisión determinada por la incapacidad-imposibilidad de realizar aquello

53 Gai. 7 ad ed. prov. D.9,2,8. Idem iuris est, si medicamento perperam usus fuerit. sed et qui bene secuerit et dereliquit curationem, securus non erit, sed culpae reus intellegitur. (1) Mullionem quoque, si per imperitiam impetum mularum retinere non potuerit, si eae alienum hominem obtriverint, volgo dicitur culpae nomine teneri. idem dicitur et si propter infirmitatem sustinere mularum impetum non potuerit: nec videtur iniquum, si infirmitas culpae adnumeretur, cum affectare quisque non debeat, in quo vel intellegit vel intellegere debet infirmitatem suam alii periculosam futuram. idem iuris est in persona eius, qui impetum equi, quo nehebatur, propter imperitiam vel infirmitatem retinere non poterit. [Trad. El mismo derecho hay, si malamente hubiere usado de un medicamento. Pero el que hubiere hecho bien la operación quirúrgica, y hubiere abandonado la curación, tampoco estará, sino que se entiende que es reo de culpa. (1) Dícese generalmente, que queda obligado por razón de culpa también el mulero, si por impericia no hubiere podido contener el ímpetu de las mulas, y éstas hubieren atropellado a un esclavo ajeno. Lo mismo se dice, también si por su poca fuerza no hubiere podido contener el ímpetu de las mulas. Y no parece justo, si la escasez de las fuerzas se cuenta para la culpa, porque nadie debe pretender hacer aquello en lo que no sabe, o debe saber, que su insuficiencia de fuerzas ha de ser peligrosa para otro. El mismo derecho hay respecto a la persona del que por impericia o falta de fuerzas no hubiere podido refrenar el ímpetu del caballo en que iba.] 
que era necesario (Schipani, 1969, p. 145; Cardilli, 2014, p. 28).

Fue precisamente en este sentido que el jurista profundizó el caso de la infirmitas, pues, pudiendo considerarse inequitativa, él consideró necesario reprobar no sólo la impericia en el curso de la actividad, sino también un error en una conducta antecedente, que consistía en decidir ejecutar una actividad peligrosa para la cual sabia o debía saber que no estaba en las condiciones físicas necesarias, la cual, siendo igualmente reprochable, se consideraba culpa y, por lo tanto, era sancionada (Cannata, 1995b, p. 61) ${ }^{54}$.

La labor de Gayo se vio reflejada en el pensamiento de juristas tardoclásicos, en este sentido se encuentra un fragmento de los Comentarios al edicto de Paulo (Pau. 22 ad ed. D.9,2,30,3 ${ }^{55}$ ), jurista del siglo III d.C., en donde la culpa, contrapuesta al dolo, fue definida usando los específicos criterios de la impericia y la negligencia.

Este interesante parecer de Paulo evidencia como ya en esta época la culpa había adoptado una noción más técnica y un lugar central en la valoración de un comportamiento. Paulo afrontó el caso de una persona que había prendido fuego a sus propias cosas (su rastrojo o maleza) y el fuego se propagó, quemando las mieles o la viña de otro causando de esta manera un perjuicio. La respuesta del jurista fue articulada en torno a la imputabilidad del daño, apreciándola desde el perfil de la culpabilidad la existencia o no de un urrere iniuria.

El jurista comenzó por aclarar con un propósito general, que también en la acción del tercer capítulo de la Lex Aquilia, es decir no sólo en el caso de un occidere, se castigaba el dolo y la culpa. Luego proyectó la solución del caso concreto, la cual articuló en torno a la culpa. Teniendo como premisa que el sujeto había prendido fuego a sus propias cosas, es decir, una actividad del todo lícita, el análisis giró en torno a si dicha conducta, desde el punto de vista subjetivo, podía, sin embargo, ser reprochable y por tanto considerada iniuria.

Tal reprochabilidad del comportamiento fue individuada en dos diversos perfiles, uno referente a la negligentia consistente en el descuido o la desatención al fuego que había sido prendido, es decir, al inobservancia del cuidado y la vigilancia que un homo diligens habría tenido cuando decide prender fuego a un bien propio, para evitar que el mismo se difundiere; por lo que la licitud de la actividad se agotaba cuando la misma se practicaba de manera negligente causando un daño a un bien ajeno.

Pero el jurista no se limitó a este supuesto, sino también, teniendo en cuenta un momento precedente al incendio de las cosas ajenas, consideró que actuaba con culpa aquel que prendía fuego en un día de fuertes vientos, pues se había actuado con impericia (Schipani, 1969, p. 360).

En esta última solución puede notarse un razonamiento similar al que realizó por Gayo, en el caso de aquel que emprende una actividad peligrosa cuando las circunstancias generaban un inminente peligro, sea aquel que monta un caballo o lleva una carreta en estado de debilidad o aquel que enciende un fuego a la intemperie en un día de fuertes vientos; todos estos casos se consideraban reprochables por cuanto imperitos, y dicho reproche hacía que aquella actividad, siendo lícita, se convirtiera en estas concretas circunstancias en non iure.

El jurista reafirmó estos dos perfiles de la culpa al final del fragmento, indicando que el sujeto

54 Cannata afirma que los dos casos proyectados por el jurista son del todo diversos, pero con un elemento común: el carretero era un profesional ejerciendo una actividad peligrosa, en cambio el jinete era un Ticio cualquiera que estaba cabalgando, lo cual era también una actividad peligrosa. Ahora, ambos sujetos respondían por impericia cuando causaban un daño por un error técnico; en cambio por culpa-negligencia, precisamente culpa-imprudencia, cuando realizaban esta actividad en un estado de salud que disminuía su capacidad de control del animal o la carreta. Estando encuadrado el análisis en el carácter peligroso de la actividad, se puede afirmar que el jurista consideraba que manejar un mulo, caballo o carreta, era una actividad técnica, y por tanto se actuaba con culpa-impericia si se realizaba sin poseer las capacidades técnicas y las condiciones físicas. Así, en materia de la Lex Aquilia, el carácter técnico de la actividad fundamentaba la responsabilidad, solución que tenía un fundamento ético-social, por cuanto, quien asumía una actividad técnica cuya indebida realización podía causar daños, debía estar en grado de realizarla correctamente.

55 Pau. 22 ad ed. D.9,2,30,3. In hac quoque actione, quae ex hoc capitulo oritur, dolus et culpa punitur: ideoquesi quis in stipulam suam ven spinam comburendae eius causa ignem immiserit et ulterius evagatus et progressus ignis alienam segetem vel vineam laeserit, requiramus, num imperitia eius aut neglegentia id accidit. nam si die ventoso id fecit, culpae reus est (nam et qui occasionem praestat, damnum fecisse videtur): in eodem crimine est et qui non observavit, ne ignis longius procederet. [Trad.: También en esta acción, que toma origen en este capítulo, se castiga el dolo y la culpa. Y por lo tanto, si para quemarlo hubiere alguno echado fuego a su rastrojo, o a la maleza, y habiéndose extendido y propagado el fuego hubiere perjudicado a las mies o a la viña de otro, investiguemos si esto sucedió por su impericia, o negligencia; porque si hizo esto en día de viento, es reo de culpa (pues también el que dio ocasión, se entiende que causó daño): en el mismo delito incurre también el que no tuvo cuidado de que el fuego no se extendiera más lejos. Pero si tuvo en cuenta en todo lo que fue oportuno, o si súbita fuerza del viento llevó más lejos el fuego, carece de culpa.] 
estaba exento de culpa cuando había observavit todo aquello que era necesario para evitar que se causara un daño, pues no había actuado con negligencia. Razonamiento que parece influenciado por la noción de culpa de Q. Mucio, en el sentido de providere todo aquello necesario para evitar el daño.

Pero además el comportamiento resultaba también justificado, cuando una subita vis venti había causado la propagación del fuego, puesto que en este caso fue el viento el que súbitamente propagó el fuego y, por tanto, era imposible de preverlo y su fuerza era imposible de resistir. Por lo tanto, el sujeto actuó con la pericia exigida a aquel que emprendía la riesgosa actividad de prender un fuego a la intemperie, puesto que lo hizo en un día que el fuerte viento no podía ser previsto, el daño no le podía ser imputado pues su actuar no era reprochable ${ }^{56}$.

En conclusión, la interpretación de la iniuria aquiliana avanzada por la jurisprudencia, gracias a la cual emergió la noción de culpa, permite comprender el verdadero significado de la definición de iniuria que Ulpiano ofreció en el ya analizado fragmento de Ulp. 18 ad ed. D.9,2,5,1, en el sentido que la culpa operaba como un criterio límite al carácter injustificado de un comportamiento, lo cual permitió pasar de un criterio objetivo de imputación jurídica de la sanción aquiliana a una imputación que implicaba, también, un juicio de reprochabilidad subjetiva.

\section{E. El evento lesivo y la estimación del damnum}

La Lex Aquilia mediante el uso de los precisos verbos legales expresaba además el tipo de lesión que resultaba relevante para la procedencia del remedio aquiliano, esto es, que una cosa ajena fuera matada, quemada, hecha pedazos o rota. En este sentido, el comportamiento típico debía causar un damnum, entendido como un perjuicio patrimonial al propietario de un bien y que consistía en la violación de la integridad física de una cosa que tuviera como consecuencia su destrucción o al menos su deterioro ${ }^{57}$.

La necesidad de que se verificara un damnum con estas características, resulta coherente con el hecho que la Lex Aquilia pretendía tutelar la propiedad, mas no en general el patrimonio, lo cual tenía como consecuencia que, en su origen, la cláusula condenatoria contemplaba solamente la liquidación del valor de la res, y que la titularidad de la acción directa estaba restringida exclusivamente al propietario $^{58}$.

Coherente con este significado y siguiendo la enunciación de Corbino (2005, p. 85; 2007, p. 607), el daño para ser relevante ex lege Aquilia debía ser: existente, cierto y estimable. Sobre la existencia del daño, Ulpiano nos da noticia afirmando que la acción directa sólo procedía cuando la conducta hubiera producido una disminución al precio del bien (Ulp. 18 ad ed. D.9,2,27,17) y, por tanto, una pérdida patrimonial al propietario. Así mismo, el damnum debía ser cierto, por ello fue excluido el reconocimiento de las ganancias o réditos futuros y eventuales que a causa del daño el propietario dejó de percibir, pues los juristas consideraron esta pérdida como incierta $y$, por lo tanto, inestimable (Ulp. 18 ad ed. D.9,2,29,3).

Por último, el damnum debía ser de naturaleza estimable, en consecuencia, fue excluido el daño que hoy conocemos como puramente moral (Ulp. 41 ad Sab. D.9,2,41 pr.), así como el reconocimiento del valor de afección que la cosa tuviera para su propietario (Pau. 2 ad Plaut. D.9,2,33 pr.), y las lesiones corporales sufridas por un hombre libre, cuyo cuerpo carecía de naturaleza estimable. Estos supuestos, en cambio, eran perseguibles mediante la actio iniuriarum aestimatoria (Ulp. 23 ad ed. D.9,3,1,5; Gai. VI ad ed. prov. D.9,3,7).

La necesidad de que el damnum fuera de naturaleza estimable surge precisamente de las cláusulas condenatorias, según las cuales, el valor que debía

56 Este razonamiento del jurista es análogo al que expresó en el caso del podador que dejaba caer una rama lesionando un esclavo ajeno (Pau. 10 ad. Sab D.9,2,31), en el cual el Paulo afirmó que, realizándose dicha actividad en lugares en los cuales no había ningún camino, el potator solo respondía por dolo, pues no podía exigirse que adivinara que alguno pasaba. Analogía que se evidencia por cuanto, tratándose de días con un viento tranquilo, en el caso del incendio o de trabajos sobre un árbol en un lugar por el que no pasan personas, no era previsible para el sujeto la circunstancia que originó el daño (el súbito viento o el súbito paso de un transeúnte) y por tanto no podía existir culpa de su parte.

57 Sobre la noción de damnum en la Lex Aquilia sostiene Valditara (1998, p. 2) que, si bien en las fuentes más antiguas en especial en la legislación decenviral, la noción de damnum significaba la lesión ocasionada al corpus de una cosa, ya en la época de aplicación del plebiscito aquiliano el concepto expresaba una pérdida económica sufrida por un propietario, pero que sin duda nunca perdió su ligamen a la lesión física de un bien.

58 Lo cual desciende del mismo lenguaje legislativo que usa en el primer capítulo la expresión erus y en el tercero dominus y es afirmado expresamente por Ulpiano en Ulp. 18 ad ed. D.9,2,11,6. Legis autem Aquiliae actio ero competit, hoc est domino. [Trad.: Mas la acción de la ley Aquilia compete al dueño, esto es, al señor] 
constituir el objeto de la condena variaba según se tratare de un daño contemplado en el primero, segundo o tercer capítulo. El primer capítulo preveía que el agente debía ser condenado a pagar a su propietario el mayor valor que la cosa hubiere tenido en el último año -quanti ea res plurimi fuit-; el segundo preveía una condena por el valor actual del crédito extinto -quanti ea res est- $y$, en el caso del tercero, se condenaba por el valor que el bien hubiere tenido en los últimos 30 días -quanti ea res $<$ fuit $>$ in debus triginta proximis-.

Por lo tanto, el criterio de valoración de la condena era originariamente el de la aestimatio rei. En el caso del primer capítulo, este mecanismo de liquidación tenía su razón de ser en que el precio de los esclavos y pecudes estaba sujeto a variaciones estacionales, por tanto, el bien tenía un valor diferente según la época del año, particularmente según los periodos de siembra, cosecha y en general los diversos eventos de naturaleza agrícola (Cardascia, 1974, p. 62; Cannata, 1995a, p. 45; Valditara, 2005, p. 43; de Robertis, 200, p. 32$)^{59}$.

En cambio, en el caso de un daño ex capite tertio, la previsión legislativa consistía en liquidar la condena por el valor que la cosa hubiera tenido en los últimos 30 días. Sobre la interpretación de la cláusula sancionatoria de este capítulo, Cannata (1995a, p. 46) y Valditara (2005, p. 44), cuya posición resulta coherente con las fuentes, afirman que originalmente la condena, tanto en el caso del primero como del tercer capítulo, consistió en el valor entero de la res. En el caso del tercer capítulo, se realizaba tomando el valor del bien en los últimos 30 días sin hacer referencia al plurimi, pues, tratándose de bienes que no estaban sujetos a variación estacional, el legislador expresaba la idea de que la pena estuviera conmensurada al valor de la cosa al momento inmediatamente anterior a su destrucción, precisando los 30 días con la finalidad de individuar un lapso suficiente para que el propietario pudiera adecuadamente probar dicho valor ${ }^{60}$

Este estado de cosas se mantuvo durante la jurisprudencia de edad augusta, como se deduce de diversos pareceres de Labeón ${ }^{61}$. Los primeros pasos a una modificación del criterio de valoración del daño, por lo menos en lo referente a la aplicación del plurimi en la liquidación de la condena ex capite tertio, fue obra de Sabino (Gai. 3,218; Ulp. 18 ad ed. D.9,2,29,8), lo cual ocurrió como consecuencia de la ampliación de la tutela ex capite tertio a los daños no destructivos (Cannata, 1995a, p. 53).

Con toda seguridad, las fuentes permiten evidenciar que sólo hasta finales del siglo I d.C., por obra especialmente de Juliano y Javoleno, se insinuó una interpretación diversa del criterio de estimación del daño que, respetando el detalle legislativo, permitió reconocer la utilitas del propietario sobre la cosa dañada. Este cambio interpretativo fue, posiblemente, un estadio intermedio entre la aestimatio rei originaria y la consolidación del id quod interest como criterio de liquidación de la condena (Valditara, 2005, p. 56) ${ }^{62}$.

El criterio del id quod interest que consistía en el reconocimiento del íntegro daño sufrido por el propietario del bien, es decir, la diferencia patrimonial entre la situación en que estaría el propietario si no se hubiera ocasionado el ilícito y la situación determinada a causa del mismo; parece haberse desarrollado tomando como base el concepto de 'precio formal', ya propuesto por la jurisprudencia anterior, y encontró su aplicación explicita en materia aquiliana en la época de Ulpiano y Paulo, de lo cual da noticia especialmente Ulp. 18 ad ed. D.9,2,21,2 y Pau. 12 ad ed. D.9,2,22,1 (Valditara, 1992, p. 291)

59 En particular de Robertis afirma que el reenvío al curso de un año anterior, desciende del arcaico ambiente agrícola propio de la época de aprobación del texto plebiscitario, en la cual, también por razones religiosas, los hombres y las bestias eran constreñidos al reposo durante el periodo invernal, pero en todo caso, debían continuar siendo alimentados y cuidados; así, era especialmente este gasto infructífero el que generaba la variación estacional del bien, que era máximo al comienzo de la primavera y mínimo al inicio del invierno.

60 En contrario, Corbino (2008, p. 700).

61 Lo cual resulta de la lectura de Ulp. 18 ad ed. D.9,2,23,4; Ulp. 18 ad ed. D.9,2,27,35. Sobre este particular: Valditara (1995, p. 78) y en contrario de Robertis (2000, p. 123).

62 Sostiene Valditara (1992, p. 58) que este estadio intermedio consistió en el reconocimiento al propietario del 'precio formal', en el cual se valoraba el precio del bien destruido o deteriorado, teniendo en cuenta la utilidad que el mismo ofrecía su propietario, estimando todos los commoda que la disponibilidad de la cosa y su integridad material le garantizaban a él. Era, en todo caso, el pretium corporis el punto de partida, al cual se le agregaba la entidad que la jurisprudencia denominó la causa rei, que representaba aquel ulterior valor que el bien tenía para su singular propietario. Ejemplos del reconocimiento del 'precio formal' resultan del parecer de Juliano en Ulp. 18 ad ed D.9,2,23,2 y de Javoleno en lavo. 14 ex Cas. D.9,2,37,1, a partir de los cuales, la jurisprudencia sucesiva desarrollaría los conceptos de daño emergente y lucro cesante. Así, este método miraba a valorar no sólo el pecio de mercado de manera estática, sino en función instrumental y dinámica, teniendo en cuenta las especificas relaciones de las que era objeto el bien y era titular su propietario, permaneciendo dentro del marco de la aestimatio rei, pero la cual era entendida como inclusiva del corpus más la causa. 
La condena en los términos antes explicados descendía del ejercicio de la actio ex lege Aquilia, cuya procedencia estaba condicionada a que la conducta y el evento tuvieran la entidad y las características que a lo largo de este escrito hemos descrito. EI remedio aquiliano fue concebido como una acción penal y la condena como una verdadera poena, lo cual resulta inequívoco, al menos hasta la jurisprudencia clásica ${ }^{63}$, especialmente porque la acción tenía las características propias de las acciones penales: la intransmisibilidad pasiva, la solidaridad cumulativa y el régimen noxal ${ }^{64}$.

Esta acción nació con una naturaleza penal a causa de la insuficiencia, en la época de la aprobación del plebiscito aquiliano, de los remedios reipersecutorios disponibles (rei vindicatio y condictio), pues ellos solo procedían cuando una cosa que existía estaba en posesión de un tercero mas no cuando la cosa dejaba de existir sea porque había muerto o había sido destruida. Así, para colmar esta laguna se introdujo una acción que permitió condenar al agente a pagar al propietario el valor de la cosa destruida, y este es el significado de la precisa expresión tantum damnas esto utilizada por el legislador, cuyo fin era originar una obligación ex delicto, consistente en el pago una suma dineraria equivalente al valor del bien destruido (Cannata, 1995a, p. 56).

La función punitiva que el legislador aquiliano pretendió otorgarle a la condena resulta, además, del hecho que su estimación consistía en el valor de mercado de la cosa, no del momento en el cual fue destruida o un simple resarcimiento, sino en el mayor valor que la cosa hubiera tenido en el último año o 30 días; condena que era pronunciada por el doble en caso de adversus infitiantem (Voci, 1939, p. 67; Corbino, 2005, p. 145). No obstante, siendo un remedio que miraba a tutelar la propiedad, la función punitiva para el sujeto agente venia complementada por una reipersecutoria o, mejor, resarcitoria para el propietario, pues el derecho de crédito del que resultaba titular sustituía el derecho de propiedad perdido (Valditara, 2005, p. 57).

La idea de que el remedio aquiliano tuviera también una función reipersecutoria, fue insinuado al menos desde finales del siglo I d.C. con el surgimiento del criterio del 'precio formal', coherente con esta idea, Gayo incluyó la actio ex lege Aquilia entre aquellas que rem et poenam persequimur (Gai. 4,6-9). Luego, esta doble función encontró confirmación en la jurisprudencia tardoclásica, como nos da noticia Paulo (Pau. 10 ad Sab. D.9,2,18; Pau. 20 ad ed. D.5,3,36,2) y Ulpiano (Ulp. 28 ed ed. D.13,6,7,1) quienes aplicaron el criterio de la prevención en caso de concurso entre la actio ex lege Aquilia y otra acción reipersecutoria. Lo anterior fue el resultado, precisamente, del hecho que en esta época se desarrollaron las premisas para la aplicación del criterio del id quod interest, que le otorgaba una naturaleza más resarcitoria a la condena y cuya confirmación resultó explicita en las Institutas de Justiniano (I.4,6,16-19), en donde la acción aquiliana fue catalogada como una acción de naturaleza mixta (Voci, 1939, p. 91; Valditara, 2005, p. 58; Albanese, 2008, p. 71).

\section{LA EXTENSIÓN DE LA TUTELA AQUILIANA MEDIANTE LA ACTIVIDAD PRETORIA}

Hasta aquí hemos analizado el contenido del plebiscito aquiliano y las condiciones de procedibilidad de la tutela mediante la actio ex lege Aquilia, junto con la labor de interpretación que la jurisprudencia realizó sobre la misma, que fue en algunos casos extensiva y, en otros, restrictiva. Sin embargo, la tutela jurídica de los daños patrimoniales no se agotó en la concesión de la acción directa o civil, pues la actividad del pretor permitió extender el ámbito de aplicación de la Lex Aquilia, mediante la concesión de diversas acciones residuales $^{65}$, que fueron diversamente nombradas en las fuentes como acciones in factum, in factum ad exemplum, utiles y accommodatae; de las cuales

63 Tal naturaleza es afirmada por Gayo -Gai. 3,202 y Gai. 7 ad ed. prov. D.9,2,32 pr.-; por Juliano -lul. 86 dig. D.9,2,51,2-; por Paulo -Paul. 22 ad ed. D.9,2,30,3-; y por Ulpiano -Ulp. 18 ad ed. D.9,2,11,2-.

64 La originalidad del carácter penal del remedio aquiliano resulta confirmado, además, porque el régimen que pretendió remplazar la legislación aquiliana, especialmente contenido en las XII Tablas, era netamente penal. (Voci, 1939, p. 91; Corbino, 2005, p. 146).

65 El carácter residual de las acciones pretorias y la función complementaria de la actividad del pretor mediante su concesión, resulta afirmado en las fuentes, especialmente en:

Pomp. 39 ad Q. M. D. 19,5,11. Quia actionum non plenus numerus esset, ideo plerumque actiones in factum desiderantur. Sed et eas actiones, quae legibus proditae sunt, si lex aiusta ac necessaria sit, supplet Praetor in eo, quod legi deest; quod facit in lege Aquilia reddendo actiones in factum accommodatas legi Aquiliae; idque utilitas eius legis exigit. [Trad.: Como no está completo el número de las acciones, por esto se requieren muchas veces las acciones por el hecho. Pero también a aquellas acciones, que están manifiestas en las leyes, si la ley fuera justa y necesaria, las suple el pretor en lo que le falta a la ley; lo que hace en la ley Aquilia dando acciones por el hecho, acomodadas a la ley Aquilia; y esto lo exige la utilidad de aquella ley.]

Pau. 2 ad Plau. D.9,2,33,1. In damnis, quae lege Aquilia non tenentur, in factum datur actio. [Trad.: Por los daños que no se comprenden la ley Aquilia, se da la acción por el hecho.] 
su primera noticia se tiene hacia el siglo I a. C. de parte de Orfilio ${ }^{66}$

La ampliación de la tutela aquiliana mediante la actividad pretoria se produjo en aquellos casos en los cuales, a pesar de que se había producido un damnum, el mismo no había sido consecuencia de una conducta que encajaba en los verba legis o cuando el damnum no fue corpore suo datum.

Respecto del capítulo primero, se concedió la acción útil contra aquel que encerraba a un animal que luego moría por inanición (Ulp. 56 ad ed. D.47,8,2,20). En cambio, procedió la acción in factum contra aquel que omitía alimentar a un animal y este moría de hambre (Ulp. 18 ad ed. D.9,2,9,2); contra el que daba un veneno en cambio de un medicamento a un esclavo y él moría a causa de su ingestión (Ulp. 18 ad ed. D.9,2,9 pr.1); contra el que daba una espada a un furioso y él se ocasionaba la muerte (Ulp. 18 ad ed. D.9,2,7,6); contra el que desnudaba a un esclavo y él moría de frio; así como contra aquel que instigaba a un animal sobre el cual estaba un esclavo, causando que el esclavo cayera al rio y muriera; y, en fin, contra el que conducía un esclavo a un lugar peligroso donde era asesinado por un tercero (Ulp. 18 ad ed. D.9,2,9,3).

En todas estas hipótesis, en efecto, no se configuraba un occidere en el sentido restrictivo que le otorgó la jurisprudencia, sino que se trataba de hipótesis de mortis causam praestare, es decir, en las cuales el agente no mató el animal o esclavo mediante una conducta directamente ejercitada sobre la cosa, sino que su conducta, activa u omisiva, dio lugar a la muerte, pero que la muerte fue causada directamente por un tercero, por la víctima o por simples eventos naturales ${ }^{67}$. Sin embargo, el pretor consideró estas hipótesis dignas de la tutela aquiliana.

Bajo los mismos presupuestos, en materia del tercer capítulo, la actio utilis fue concedida contra aquel que consumió cosas ajenas que eran por su naturaleza consumibles (Pau. 22 ad ed. D.9,2,30,2); y contra el que descuidó negligentemente un horno que otro había encendido y, como resultado de ello, se quemó un bien ajeno (Ulp. 18 ad ed. D.9,2,27,9). En cambio, concedió la actio in factum en los casos en los cuales alguno había causado el extravió o distracción de una cosa ajena (Alf. 3 dig. D.19,5,23; Proc. 2 epist. D.41,1,55); contra aquel que mezclaba materiales ajenos, cuya separación no era imposible pero sí molesta o difficilis (Ulp. 18 ad ed. D.9,2,27,14/20); contra el que había liberado a un esclavo de sus cadenas, no con dolo, sino inducido por la compasión -misericordia ductus(Ulp. 11 ad ed. D.4,3,7,7); también contra aquel que estaba quemando su propia paja y el fuego se extendió y quemó la casa vecina (Coll. XII,7,4-5); y contra quien había provocado humo y ello dio lugar a la fuga o muerte las aves ajenas -que no eran animales considerados pecudes- (Ulp. 9 disp. D.9,2,49 pr.).

Como podemos evidenciar, en estos casos no se configuraba una conducta sancionada ex capite tertio, a pesar de la extensiva interpretación jurisprudencial del verbo rumpere, sea porque el sujeto agente no realizó ninguna conducta activa o porque, habiendo actuado, no hubo un contacto directo y material entre el agente y la cosa, por tanto, el daño no era directamente conducible a él o, en fin, porque no se produjo una corruptio rei y por ello no era un damnum tutelado ex lege Aquilia (Corbino, 2005, p. 152).

Con todo, la concesión de la tutela del pretor no estuvo ligada solamente a casos de ausencia de alguno de los elementos estructurales del ilícito, sino también a aquellos de ausencia de la titularidad de la acción directa. En este sentido, el pretor consideró que eran merecedores de tutela aquiliana quienes fueran titulares de iura in re aliena, concediendo la actio utilis al usufructuario (Pau. 3 ad Vite. D.7,1,17,3; Ulp. 18 ad ed. D.9,2,11,10; Pau. 10 ad Sab. D.9,2,1), al comodatario (Ulp. 18 ad ed. D.9,2,11,9-10), al acreedor pignoraticio (Pau. 22 ad ed. D.9,2,30,1) y al titular de una servidumbre (Ulp. 18 ad ed. D.9,2,17,32) cuando se ocasionaban daños sobre las cosas objeto del derecho real.

La imposibilidad de la tutela aquiliana al non dominus mediante la acción directa descendía, por un

66 Ulp. 18 ad ed. D.9,2,9,3. Si servum meum equitantem concitato equo effeceris in flumen praecipitari ideo homo perierit, in factum esse dandam actionem Ofilius scribit: quemadmodum si servus meus ab alio in insidias deductus, ab alio esset occisus. [Trad.: Si habiendo hostigado al caballo hubieses hecho que mi esclavo que lo montaba se precipitase en el rio, y por esto hubiere perecido el esclavo, escribe Orfilio, que se ha de dar la acción por el hecho, de la misma manera que si llevado por uno mi esclavo a una emboscada hubiese sido muerto por otro.]

Del uso de la expresión in factum ese dandam actionem (debe ser dada una acción in factum), y del hecho que sea la primera noticia que ofrece las fuentes sobre este tipo de acciones, se ha concluido que Orfilio hacía una sugerencia al pretor y, por tanto, que pretendía impulsar una práctica que podría ser aún tímida e incierta (Corbino, 2005, p. 152).

67 Sobre la distinción entre occidere y mortis causam praestare en materia aquiliana y la tutela in factum del segundo supuesto, se tiene noticia por primera vez de parte de Orfilio en Ulp. 18 ad ed. D.9,2,9,3 y fue expresamente propuesto por Celso en Ulp. 18 ad ed. D.9,2,7,6. (Valditara, 2005, p. 23). 
lado, de la finalidad misma de la legislación aquiliana, la tutela a la propiedad; y, por el otro, del régimen de liquidación de la condena mediante la aestimatio rei, que implicaba una reintegración patrimonial equivalente a la merma sufrida por la destrucción de un bien de su propiedad. Por lo tanto, la adaptación del método de liquidación al criterio del id quod interest, permitió que el pretor concediera tutela aquiliana al daño sufrido por el titular de un iura in re aliena, cuando la cosa objeto de tal derecho era destruida o deteriorada, pues en estos casos el juez liquidaba la condena con base en el específico perjuicio sufrido.

Por esta razón, resulta coherente que la primera noticia acerca de la posibilidad de conceder la acción útil al non dominus sea de Juliano, quien dio los primeros pasos en la transformación del régimen liquidatario, y que tal posibilidad hubiera sido expresamente afirmada por Paulo y Ulpiano, juristas que concretaron la aplicación del id quod interest en la época tardoclásica (Valditara, 1992, p. 447; 2005, p. 54).

El alargamiento de la tutela aquiliana, facilitada por la trasformación del criterio de liquidación al id quod interest, no abarcó solamente a los titulares de derechos reales, sino también otras situaciones de hecho. En este sentido, mediante actio in factum fue tutelado el poseedor de buena fe de un bien, cuando el mismo fuera destruido por su propietario (Ulp. 18 ad ed. D.9,2,17 pr.), y mediante la acción útil se tuteló al poseedor en el caso de una occisio de un hombre libre, pero que estaba poseído de buena fe como esclavo (Ulp. 18 ad ed. D.9,2,13 pr.).

Como se concluye de los casos antes referidos, la actividad pretoria, facilitada por la reinterpretación jurisprudencial de las cláusulas sancionatorias, comportó la mutación de la función de la tutela aquiliana, pues dejó de proteger solo la propiedad; para defender el patrimonio en sí mismo considerado.

En cuanto al problema de la diversidad de expresiones utilizadas para designar las acciones pretorias aquilianas -in factum, in factum ad exemplum, utiles y accommodatae-, este ha sido un tema profundamente discutido por la doctrina $y$ su atento análisis excede los alcances de este es- tudio. No obstante, basta indicar que la doctrina romanista ha realizado varios intentos por encontrar una sistematización coherente (Valiño, 1973, p. 3; Corbino 2005 , p. 166), a pesar de que, como afirma Ziliotto (2000, p. 61), resulta evidente el uso promiscuo e indiscriminado de estas expresiones en las fuentes a nosotros disponibles. Esta autora, luego de relatar las principales teorías propuestas por diversos doctrinantes y proponer las críticas pertinentes a cada una, ofrece una hipótesis que resulta del todo atendible.

En primer lugar, afirma la autora, tomando como base la conceptualización hecha por Mario Talamanca (2008, p. 51), que la expresión actio in factum se utilizaba, de manera general, en las fuentes en dos diferentes sentidos: en el sentido de una acción con fórmula in factum concepta y en el sentido de una acción decretal (Ziliotto, 2000, p. $53)^{68} y$, posiblemente, en materia aquiliana, cuando las fuentes nos dan noticia de la concesión de una actio in factum, la expresión se utilizaba en la segunda acepción. Luego, las acciones útiles, generalmente contrapuestas a las acciones directas, eran aquellas en las cuales se modificaba la estructura formular para adaptarla a las necesidades del caso concreto, extendiendo el campo de aplicación de una acción edictal, sea mediante una fictio, una trasposición de sujetos o la construcción de una fórmula in factum concepta (Ziliotto, 2000, p. 87; Talamanca, 2008, p. 62).

Si se interpreta en este sentido la noticia de Pomponio (Pomp. 39 ad Q. M. D.19,5,1169), se deduce que el jurista quiso afirmar, en la primera parte del fragmento, que el pretor completaba las acciones del edicto mediante acciones particulares; por lo tanto, la expresión actio in factum la usó para referirse a las acciones decretales, sin hacer referencia a su estructura formular, pues el jurista precisamente fundó su explicación en la insuficiencia de las acciones propuestas en el edicto (Ziliotto, 2000, p. 91).

Luego, en la segunda parte del fragmento, el jurista indicó que el pretor completaba también las acciones que eran creadas sobre la base de las leyes, para colmar sus lagunas cuando era justo y necesario, como sucede, afirmó el jurista, en las acciones pretorias concedidas en materia de la Lex Aquilia. Para referirse a estas acciones, usó

68 Las primeras, eran aquellas cuya estructura formular implicaba la ausencia en la pretensión (intentio) de toda referencia en términos de derecho, es decir, la fórmula estaba sustentada en los hechos, sin que se incluyera ningún derecho del actor y ninguna obligación a cargo del demandado, tal como las define Gayo en su texto institucional (Gai. 4,45). En cambio, las acciones decretales eran aquellas que el pretor concedía para un singular y concreto supuesto de hecho, sin que haya sido prevista previamente en el edicto.

69

Cfr. supra. 
la denominación in factum accommodatae legi Aquiliae, en la cual, la genérica expresión accommodatae, que sería sinónimo de ad exemplum, implicaba el reenvío al modelo de la acción civil o directa; sin que el jurista haya hecho referencia a la estructura formular de dichas acciones, es decir, al instrumento utilizado por el pretor, que podía ser una fictio o una fórmula in factum concepta, por lo tanto, el jurista se estaba refiriendo, en esta segunda parte del fragmento, a las acciones útiles (Ziliotto, 2000, p. 92).

Lo anterior permite concluir que no se trataban de dos acciones sustancialmente contrapuestas y diseñadas para hipótesis diferentes y excluyentes, sino que eran acciones que operaban en planos diferentes y que, de hecho, podían ser complementarias; por cuanto una acción era útil, si era adaptada tomando como base una acción edictal, sea mediante una fictio o simplemente con una fórmula in factum concepta, y además era in factum si la misma era concedida por el pretor para el caso concreto, mas no prometida en su edicto anual.

\section{EL DAMNUM INIURIA DATUM EN LA COM- PILACIÓN JUSTINIANEA}

Nos resta realizar algunas anotaciones respecto al régimen justinianeo, especialmente aquel plasmado en el Digesto, por cuanto el texto institucional en materia aquiliana siguió a grandes rasgos las Instituciones de Gayo. Por un lado, dada la precedente emersión de nuevos crímenes públicos que individuaban conductas asimilables a los supuestos de los delitos privados, en el Digesto la unidad de los maleficia se fraccionó ${ }^{70}$. En este sentido, el furtum, la rapina y la iniuria-contumelia fueron tratados en los libros 47 y 48 de la obra compilatoria, por lo que se acentuó su perfil de reprochabilidad social y se convirtieron en auténticos crímenes públicos (Schipani, 2009, p. 147).

En cambio, el cuarto delito, el damnum iniuria datum, constituyó el núcleo del libro 9 del Digesto, cuyo título 2 fue dedicado enteramente al ilícito aquiliano (Cerami 1995, p. 105) ${ }^{71}$. La disciplina aquiliana de Justiniano no presentó significativas novedades respecto a los elementos estructurales del ilícito, más allá de los aspectos relacionados con la superación cualquier diferencia sustancial entre el régimen civil y el pretorio. A pesar de que se haya mantenido su recuerdo de esta diferencia, el ilícito aquiliano, en su tutela civil y pretoria, fue prevista con una la lógica del todo unitaria, lo cual contribuyó a la posterior consagración de una acción general de resarcimiento del daño (Corbino, 2005, p. 171).

Por lo que con Justiniano se concluyó el largo proceso evolutivo del ilícito previsto en la Lex Aquilia aproximadamente siete siglos atrás, manteniéndose como una conducta típica, a pesar de la flexibilidad en la interpretación de sus verbos, que ocasionaba un daño patrimonial a otro; conducta que además debía ser cometida con iniuria, lo cual presuponía una ilicitud objetiva y una reprochabilidad subjetiva; la cual tenía como consecuencia la imposición de una condena pecuniaria, con una función penal y también resarcitoria, última función que se acentuó gracias a la progresiva emersión del criterio del id quod interest (Valditara, 2005, p. 86).

Así, en el Digesto se cristalizó la idea según la cual quien causaba un daño a otro, sin una justificación y con dolo o culpa, tenía la obligación de pagar a la víctima el valor del daño causado. Esta estructuración del ilícito aquiliano fue a la postre objeto de recepción e interpretación por la ciencia jurídica intermedia y por la escuela iusnaturalista, cuyas conceptualizaciones influyeron en el movimiento codificador europeo de fines del siglo XVIII, que a su vez resultó la base de los códigos latinoamericanos. Por lo que el plebiscito que el Tribuno Aquilio hizo aprobar en el siglo III a. C. es el origen del moderno régimen de responsabilidad extracontractual o, también llamada evocando sus ancestros, aquiliana.

\section{CONCLUSIONES}

1. La Lex Aquilia estaba compuesta de tres capítulos que regulaban tres diversos supuestos de daño patrimonial y por dos cláusulas de naturaleza procesal. Los capítulos primero y tercero disciplinaban el ilícito denominado damnum iniuria datum, el cual estaba compuesto por determinados elementos

70 La categoría de maleficia, compuesta por los cuatro delitos privados sintetizada por Gayo (Gai. 3,182), se mantuvo aún hasta el texto Institucional de Justiniano (I.4,1, pr.).

71 Sobre el particular, afirma Cerami que la diversa perspectiva entre las Instituciones y el Digesto de Justiniano fue relevante, en el sentido que mientras en las primeras los compiladores, siguiendo el modelo gayano, estructuraron el tema del delicto desde el punto de vista de las fuentes de la obligatio; en el Digesto, en cambio, fue estructurado desde el punto de vista de la función esencialmente reparadora de las acciones establecidas en el libro IX (la actio de pauperie, la actio ex lege Aquilia, la actio de effusis vel deiectis y las actiones noxales). Así, a la idea del delictum y el quasi delictum como fuente de obligaciones, presente en los textos institucionales, se sobrepuso, mediante el libro IX del Digesto, la idea del damnum causado por un acto o hecho ilícito que comportaba la obligación de resarcirlo. 
estructurales: una conducta típica (occidere, urrere, frangere, rumpere); un nexo causal de carácter material (corpore suo datum); la iniuria; y el damnum. Cuando una conducta se subsumía estos elementos daba lugar a la concesión de una acción ex delicto, la cual tenía por finalidad imponer una sanción pecuniaria al agente y en favor de la víctima, con función punitiva, a la vez que, de reequilibro patrimonial y de tutela del derecho de propiedad de la víctima.

2. La interpretación de las previsiones de la Lex Aquilia por parte de los prudentes romanos fue, en algunos casos, de carácter restrictivo, como sucedió con verbo occidere o con la necesidad de que el daño fuera causado mediante un contacto directo y material. Empero, la mayoría de los elementos del ilícito fueron interpretados de manera bastante amplia, lo cual contribuyó a que este supuesto se convirtiera en el mecanismo de tutela de daños patrimoniales por antonomasia. En particular, la interpretación del verbo rumpere como corrumpere permitió incluir dentro de la tutela aquiliana todo tipo de alteración que sufriera una cosa, aunque no fuera destructiva; igualmente, el hecho de que la cláusula condenatoria hubiera sido reinterpretada, para reconocer a la víctima el id quod interest -a cambio de la originaria aestimatio rei- permitió compensar a través de la acción aquiliana toda clase de merma patrimonial surgida por alguno, aunque no fuera el propietario de la cosa dañada.

3. En lo que tiene que ver con la iniuria, este término fue empleado por el legislador como un ablativo de modo, y su función fue cualificar los verba legis. Tal cualificación consistía en que la conducta debía ser non iure, es decir, que debía carecer de una causa que la justificara frente al ordenamiento jurídico. En el seno de la interpretación de la iniuria, desde la jurisprudencia de Q. Mucio en época tardo republicana, emergió el concepto de la culpa como un límite a la estricta aplicación de una causa de justificación, lo cual llevó a considerar que, si una conducta, a pesar de estar objetivamente justificada, era subjetivamente reprochable, pues había sido intencional o se había alejado del modelo ideal de comportamiento del homo diligens, debía ser igualmente sancionada.

Este concepto de culpa sufrió gradualmente un proceso de decantación y especificación por obra de la jurisprudencia clásica, que se manifestó tanto en la contraposición de las conductas intencionales a aquellas realizadas con culpa, surgiendo el binomio dolo-culpa; como en la identificación de la culpa con específicos criterios, tales como la negligentia, la imperitia y la infirmitas. Esto significó el paso de un régimen objetivo de imputación jurídica de la sanción aquiliana, a una imputación que implicaba, no sólo un juicio de licitud de la conducta, sino también uno de reprochabilidad subjetiva. Así, la jurisprudencia construyó un criterio de imputación basado en la relación entre iniuria y culpa, relación que no implicó nunca una sustitución, sino una sinergia entre los dos conceptos, pues la culpa se insertaba dentro de la iniuria, ya que la culpa permitía restituirle al comportamiento del agente, aquella ilicitud que una causa de justificación le había quitado, y por ello actuar con culpa era actuar con iniuria.

4. No solamente la jurisprudencia contribuyó a la ampliación del ámbito de tutela de la Lex Aquilia, pues lo hizo también el pretor a través de la concesión de diversas acciones in factum, in factum ad exemplum, utiles y accommodatae. Esta ampliación se produjo en aquellos casos en los cuales, a pesar de que se había producido un damnum, el mismo no había sido consecuencia de una conducta que encajaba en los verba legis o cuando el damnum no había sido corpore suo datum. Adicionalmente, la concesión de la tutela del pretor a través de estas acciones no estuvo ligada solamente a casos de ausencia de alguno de los elementos estructurales del ilícito, sino también a la ausencia de la titularidad de la acción directa. Así, el magistrado consideró que eran merecedores de tutela aquiliana quienes fueran titulares de iura in re aliena, en particular, el usufructuario, el acreedor pignoraticio y el titular de una servidumbre. Esta ampliación transformó la función misma de la tutela aquiliana, pues dejó de proteger solo la propiedad, para proteger el patrimonio en sí mismo considerado.

\section{REFERENCIAS}

Albanese, B. (1950). Studi sulla legge Aquilia. En: Annali del Seminario Giuridico. Palermo: Università di Palermo.

Albanese, B. (2008). Voz Illecito (storia). En: Enciclopedia del diritto. Volumen XX. Milán: Dott. Antonio Giuffrè Editore.

Astolfi, R. (1993). Sabino e la 'culpa ex lege aquilia'. En: Studia et documenta historiae et iuris 59, pp. 315-320. 
Bignardi, A. (1997). Frangere e rumpere nel lessico normativo e nella interpretatio prudentium. En: Nozione formazione e interpretazione del diritto dall'età romana alle esperienze moderne 1, Nápoles: Jovene.

Bignardi, A. (2000). Gai 3,219 e il principio del damnum corpore datum. En: Archivio giuridico "Filippo Serafini" 220. Módena: Mucchi.

Cannata, C. A. (1971). Genesi e vicende della colpa aquiliana. En: Labeo 17. Nápoles: Jovene.

Cannata, C. A. (1990). Delitto e obbligazione. En: Illecito e pena privata in età repubblicana. Nápoles: Edizioni Scientifiche Italiane.

Cannata, C. A. (1995a). Sul testo della lex Aquilia e la sua portata originaria. En: VACCA, L. (ed.). La responsabilità civile da atto illecito nella prospettiva storico-comparatistica: I Congresso Internazionale ARISTEC: Madrid 1993. Turín: Giappichelli.

Cannata, C. A. (1995b). Sul problema della responsabilità nel diritto privato romano. Catania: Torre.

Cannata, C. A. (1995-1996). II terzo capo della lex aquilia. En: Bullettino dell'Istituto di Diritto Romano "Vittorio Scialoja" 37-38. Milán: Dott. Antonio Giuffrè Editore.

Cannata, C. A. (2012a). Sul testo originale della lex Aquilia: premesse e ricostruzzione del primo capo. En: Scritti scelti di diritto romano 2. Turín: Giappichelli.

Cannata, C. A. (2012b). Considerazioni sul testo e la portata originaria del secondo capo della "Lex Aquilia". En: Scritti scelti di diritto romano. Quinto volumen. Turín: Giappichelli.

Cardascia, G. (1974). La portée primitive de la Loi Aquilia, Edimburgo: Scottish Academic Press.

Cardilli, R. (1995). L'obbligazione di 'praestare' e la responsabilità contrattuale in diritto romano, Milán: Dott. Antonio Giuffrè Editore.

Cardilli, R. (2014). Gestione empirica dell'imputazione e "culpae adnumeratio» nella riflessione dei giuristi romani. En: Index 74. Nápoles: Jovene.

Castillo, M. del (1994). Estudio sobre la casuística de las lesiones en la jurisprudencia romana. Madrid: Dykinson.
Cerami, P. (1995). La responsabilità extracontrattuale dalla compilazione di Giustiniano ad Ugo Grozio. En: La responsabilità civile da atto illecito nella prospettiva storico-comparatistica: I Congresso Internazionale ARISTEC: Madrid 1993. Turín: Giappichelli

Corbino, A. (2005). II danno qualificato e la lex Aquilia. Padua: Casa Editrice Dott. Antonio Milani-CEDAM.

Corbino, A. (2007). Danno, lesioni patrimoniali e lex aquilia nell'esperienza romana. En: Scritti per Gennaro Franciosi. Nápoles: Satura.

Corbino, A. (2008). L'oggetto della aestimatio damni nella previsione del primo e del terzo capitolo del plebiscito aquiliano. En: Studi in onore di Remo Martini. Volumen 1. Milán: Dott. Antonio Giuffrè Editore.

Cursi, M. F. (2002). Iniuria cum damno, antigiuridicità e colpevolezza nella storia del danno aquiliano. Milán: Dott. Antonio Giuffrè Editore.

Cursi, M. F. (2010). Danno e responsabilità extracontrattuale nella storia del diritto privato. Nápoles: Jovene.

Daube, D. (1936). On the Third Chapter of the Lex Aquilia. Oxford: Law Quarterly Review 52.

García del Corral, I. (trad.) (1889). Cuerpo del Derecho Civil Romano. Barcelona: Ed. J. Molinas.

Gioffredi, C. (1980). In tema di 'iniuria' sui fattori di formazione del diritto romano in eta preclassica. En: Nuovi studi di diritto greco e romano. Roma: Pontificia Universitas Lateranensis.

Grosso, H. (1965). La distinzione fra 'res corporales' e 'res incorporales' e il secondo capo della 'lex Aquilia', En: Synteleia.

Gayo (1985, edición moderna). Instituciones. Traducción de Juan Iglesias Redondo; Manuel Abellán Velasco; Juan Antonio Arias Bonet y Jaime Roset Esteve. Madrid: Civitas.

Lévy-Bruhl, H. (1958). Le deuxième chapitre de la Ioi Aquilia. En: RIDA 5.

Mommsen, T. y Paul Krüger (eds.) (1870). Corpus Iuris Civilis - Digesta - Iustiniani Augusti. Berlín: Weidmannsche Buchhandlung.

Piro, I. (2004). Damnum 'corpore suo', dare rem 'corpore' possidere, Nápoles: Edizioni Scientifiche Italiane. 
Pugsley D. (1972). The lex Aquilia. En: South African Law Journal 89.

Robertis, F. de (2000). Damnum iniuria datum: Trattazione sulla responsabilità extracontrattuale nel diritto romano con particolare riguardo alla lex Aquilia de damno. Bari: Caccuci.

Rotondi, G. (1916). Dalla lex Aquilia all'art. 1151 cod. civ. - ricerche storico-dogmatiche (P. I). En: Rivista di diritto commerciale 14. Milán: Francesco Vallardi.

Sánchez Hernández, L. (2016). De la culpa de la lex Aquilia del derecho romano al principio de la responsabilidad por culpa en el derecho civil colombiano. En: Revista de Derecho Privado 30, pp. 287-335. DOI: https://doi. org/10.18601/01234366.n30.10.

Schipani, S. (1969). Responsabilità "ex lege Aquilia" criteri di imputazione e problema della "culpa". Turín: Giappichelli.

Schipani, S. (2009). Contributi romanistici al sistema della responsabilità extracontrattuale. Turín: Giappichelli.

Seckel, E. y B. Kübler (eds.) (1909). Gai Institutiones. Leipzig: Teubner.

Talamanca, M. (1990). Istituzioni di diritto romano. Milán: Dott. Antonio Giuffrè Editore.

Talamanca, M. (2000). Il riordinamento augusteo del processo privato, En: Gli ordinamenti giudiziari di Roma imperiale. Nápoles: Edizioni Scientifiche Italiane.

Talamanca, M. (2008). Voz II proceso civile (diritto romano). en: Enciclopedia del diritto. Volumen XXXVI. Milán: Dott. Antonio Giuffrè Editore.
Tomulescu, C. (1970). Les trois chapitres de la lex Aquilia. En: Iura 21.

Valiño del Río, E. (1973). Acciones pretorias complementarias de la acción civil de la ley Aquilia. Pamplona: Editorial Universidad de Navarra S.A. - EUNSA.

Valditara, G. (1992). Superamento dell'“Aestimatio Rei" nella valutazione del danno aquiliano ed estensione della tutela ai "Non Domini". Milán: Dott. Antonio Giuffrè Editore.

Valditara, G. (1995). Dall'aestimatio rei all'id quod interest nell'applicazione della condemnatio aquiliana. En: La responsabilità civile da atto illecito nella prospettiva storico-comparatistica: I Congresso Internazionale ARISTEC Madrid 1993, Turín: Giappichelli.

Valditara, G. (1998). Sulle origini del concetto di damnum. Turín: Giappichelli.

Valditara, G. (2005). Damnum iniuria datum. Turín: Giappichelli.

Valditara, G. (2009). Dalla iniuria alla culpa - Su una dibattuta questione. En: Studia et documenta historiae et iuris 75, pp. 131-145.

Voci, P. (1939). Risarcimento e pena privata nel diritto romano classico. Milán: Dott. Antonio Giuffrè Editore.

Voci, P. (1990). 'Diligentia', 'custodia', 'culpa': i dati fundamentali. En: Studia et documenta historiae et iuris 56, pp. 29-143.

Ziliotto, P. (2000). L'imputazione del danno aquiliano. Padua: Casa Editrice Dott. Antonio Milani - CEDAM. 